\title{
BORROWING CONSTRAINTS AND THE RETURNS TO SCHOOLING
}

\author{
Stephen Cameron \\ Christopher Taber
}

Working Paper 7761

http://www.nber.org/papers/w7761

\author{
NATIONAL BUREAU OF ECONOMIC RESEARCH \\ 1050 Massachusetts Avenue \\ Cambridge, MA 02138 \\ June 2000
}

For helpful comments we thank Joe Altonji, Tim Conley, Lance Lochner, Bruce Meyer, Larry Kenny, Craig Olson, and seminar participants at Brigham YoungUniversity, the Federal Reserve Bank of New York, MIT, Northwestem, Princeton, University of Florida, and the University of North Carolina. We thank Tricia Gladden for superior research assistance and thoughtful comments. We alsothank Jeff Kling for providing us with his data. For financial support, Taber acknowledges NSF Grant SBR-97-09-873, and Cameron acknowledges NSF Grants SBR-97-30657. The views expressed herein are those of the authors and not necessarily those of the National Bureau of Economic Research.

(C) 2000 by Stephen Cameron and Christopher Taber. All rights reserved. Short sections of text, not to exceed two paragraphs, may be quoted without explicit permission provided that full credit, including $\mathbb{C}$ notice, is given to the source. 
Borrowing Constraints and the Returns to Schooling

Stephen Cameron and Christopher Taber

NBER Working Paper No. 7761

June 2000

\begin{abstract}
To a large degree, the expansion of student aid programs to potential college students over the past 25 years in the United States has been based on the presumption that borrowing constraints present an obstacle to obtaining a college education. Economists and sociologists studying schooling choices have found empirical support for college subsidies in the well-documented, large positive correlation between family income and schooling attainment. This correlation has been widely interpreted as evidence of credit constraints. Recently, however, Cameron, and Heckman (1998, 2000), Keane and Wolpin (1999), and Shea (1999) have questioned whether borrowing constraints plays any role on college choices.

Over the last 30 years, a separate literature in economics has aimed at estimating measured returns to schooling purged of various biases. One potential source of bias arises when students have differential access to sources of credit for educational investments. The connection between credit access and returns to schooling-first articulated by Becker (1972)- has been recently explored by Lang (1993) and Card (1995a, 2000). Lang and Card term this bias "discount rate bias," and argue it can help explain anomalously high instrumental variables estimates of returns to schooling documented by a multitude of empirical researchers. This argument implicitly suggests borrowing constraints are important for schooling decisions.

Our paper attempts to integrate and reconcile these two literatures. Building on the seminal work of Willis and Rosen (1979), we develop a framework that allows us to study schooling determinants and returns together. Identification of the effect of borrowing constraints arises from the fact that foregone earnings-the indirect costs of school-and the direct costs of schooling affect borrowing constrained persons differently from unconstrained individuals. We apply this idea using least-squares, instrumental variables regression, and a structural economic model to measure the extent of borrowing constraints on schooling choices. Because returns to schooling and quantity of schooling are jointly determined, the structural approach allows us to explore the importance of credit market constraints on schooling choices once the influences of ability and relative wages are parceled out. This type of experiment cannot be done in standard models of schooling-attainment. None of these methods produces evidence of borrowing constraints.
\end{abstract}

Stephen Cameron

Department of Economics

Mail Code 3323

Columbia University

2960 Broadway

New York, NY 10027-6902

sc337@columbia.edu
Christopher Taber

Department of Economics

Northwestern University

2003 Sheridan Road

Evanston, IL 60208

and NBER

ctaber@northwestern.edu 


\section{Introduction}

Do borrowing constraints influence education outcomes of children? The importance of the answer to this question for the design of education policy and a number of economic phenomena goes without saying. Numerous studies by economists and sociologists have attacked this question almost exclusively through studies of the correlation between family income (or other family characteristics) and schooling attainment or specific levels of attainment $\Gamma$ college entry in particular. The positive correlation between family income and schooling has been widely interpreted as evidence supporting the idea that borrowing constraints hinder educational choices. However $\Gamma$ the step from correlation to causation is a precarious one as family income is also strongly correlated with secondary school achievement and other characteristics associated with college entry.

Recent work by Cameron and Heckman (1998Г2000) ГKeane and Wolpin (1999)Гand Shea (1998) has attempted to better understand the determinants of schooling choices. Using very different methods $\Gamma$ these researchers have found little evidence that favors the idea that borrowing constraints hinder college-going or any other schooling choice.

Over the last 20 years $\Gamma$ a separate literature in economics has aimed at estimating the return to schooling purged of "ability bias." One would expect unobserved ability to upwardly bias least-squares estimates of returns to schooling. However $\Gamma$ using instrumental variables methods to correct for the bias $\Gamma$ researchers have employed a variety of different instruments and have generally found that instrumental variables produces estimated schooling returns that are larger $\Gamma$ not smaller $\Gamma$ than least-squares estimatesThe connection between 'access to credit and measured returns to schooling-a connection noted by Becker (1972)-has been explored recently by Lang (1993) and Card (1995a 2000$) \Gamma$ who argue that "discount rate bias" can explain the anomalously high instrumental variables estimates. This argument implicitly suggests that borrowing constraints are important for schooling decisions. $^{1}$

Our paper attempts to integrate and reconcile these two literatures. Identification of borrowing constraints in all of our empirical approaches builds on the following implication

\footnotetext{
${ }^{1}$ We use the term "borrowing constraint" broadly. It does not necessarily include only hard constraints. We interpret a borrowing rate higher than the market interest rate as a borrowing constraint.
} 
of the model. When educational borrowing constraints are operating $\Gamma$ opportunity costs of schooling (foregone earnings) and direct costs (such as tuition) influence schooling choices differently for credit-constrained and unconstrained individuals. As direct costs need to be financed during school $\Gamma$ they impose a relatively larger burden on credit constrained students. Foregone earnings generally do not need to be financed during school and do not place a higher burden on credit-restricted students.

We make three contributions in this paper. First $\Gamma$ we present an empirically-tractable economic model of human capital accumulation under credit constraints. The model is novel in several ways made clear below. Second $\Gamma$ we develop the econometric methodology to estimate the model. By articulating our behavioral assumptions with simple economic theory $\Gamma$ we clarify the economic assumptions needed for empirical identification of credit constraints. We then formally demonstrate the manner in which these exclusion restrictions deliver identification in our structural model. We then explicitly use this theory to guide our econometric approach to estimating the model. The econometric methodology nests recent empirical work that studies heterogeneous returns to education as a local average treatment effect problem (Angrist and ImbensГ1993) and extends these ideas into a structural specification.

The third contribution of this paper is empirical. Working from the economic model $\Gamma$ ve present evidence on the importance of borrowing constraints from five different estimation techniques-linear regression estimates of returns to schooling Tinstrumental variable estimates of returns to schooling $\Gamma$ a simple discrete-choice analysis of schooling determinants $\Gamma$ and two structural econometric models. We discuss the instruments we use to identify both foregone earnings and the direct costs of schooling and show they are powerful predictors. Our findings are consistent across the approaches: we find no evidence of borrowing constraints.

It is important to highlight that we cannot address whether students have perfect access to credit. During the period covered by our data $\Gamma$ there are large subsidies to shool already in place in the United States. Given the policy regime $\Gamma$ we find no evidence that credit constraints restricts investments in secondary school and college. Our evidence suggests that on the margin $\Gamma$ policies aimed atimproving access to credit will have little impact on overall schooling attainment. 
This paper unfolds as follows. Section two provides a review of the literature. Section three presents the economic model on which we base our empirical strategy and discusses identification of borrowing constraints. Section four overviews the data $\Gamma$ and section five presents empirical evidence on the question of borrowing constraints from linear regression and instrumental variable estimates of the returns to education and from regression and discrete-choice analyses of schooling attainment. Section six discusses estimation of the structural model. The model jointly imposes the implications of borrowing constraints on the schooling returns and schooling attainment choices. Empirical findings follow. The paper concludes with a summary.

\section{Background and Significance}

Few empirical studies have integrated educational attainment and returns to schooling in a coherent framework. An important exception is Willis and Rosen (1979) $\Gamma$ whith our paper builds upon in a number of ways. Most research relevant to the question of educational financing constraints comes mainly from research on the determinants of schooling but also from research on the returns to education. The relevant parts of both literatures are discussed below.

\subsection{Literature on Educational Attainment Returns to Schooling}

A ubiquitous empirical regularity that emerges from the literature on determinants of schooling is that family income is strongly correlated with schooling attainment. This correlation has been found in legions of U.S. data sets covering the entire 20th century (see Hauser 1993ГKane 1994ГMayer 1997ГManski 1993ГManski and Wise 1983ГMare $1980 \Gamma$ Duncan and LevyГ1999ГCameron and Heckman 1998Гand Cameron and HeckmanГ2000Г to name a few) and in data from dozens of other countries in all stages of political and economic development (see Blossfeld and Shavit $\Gamma 1991 \Gamma$ for instance)Educational financing constraints has been the most popular behavioral interpretation of the schooling-family income correlation.

However limited credit access is only one of many possible interpretations of this correlation. Family income and other family background measures have been found to be 
correlated with achievement test performance in elementary and secondary school as well as with schooling continuation choices at all levels of schooling from elementary school through graduate school. Cameron and Heckman (2000 and 1998) adopt a 'life-cycle' view of the importance of family income and other family factors and find that family income is a prime determinant of the string of schooling-continuation decisions that lead to high school graduation and college entry. They conclude that the measured influence of the correlation between family income and college continuation is largely a proxy for its influence on earlier achievement.

Shea's findings (1996) support this interpretation of the data. Shea examines unpredictable components of family income and finds little or no correlation with children's schooling and future earnings. ${ }^{2}$ Keane and Wolpin (1999) take a different approach. They estimate a rich discrete dynamic programming model of schooling $\Gamma$ work $\Gamma$ and savings. Model simulations reveal that relaxing borrowing constraints has almost no effect on schooling $\Gamma$ though borrowing constraints are important determinants of working during school.

\subsection{Returns to Education Literature}

A large literature in labor economics has been concerned with estimating the causal effect of schooling on earnings. Ordinary least squares regressions of earnings on schooling have long been believed to be biased upward as a result of "ability bias:" individuals who attain higher levels of schooling do so because they are smarter and earn a return on their higher ability as well as on their additional years of education. Omitting measures of ability in a regression study of wages or earnings biases estimated returns to schooling upward. Empirically $\Gamma$ evidence for this idea has been found in virtually ery data set with pre-labormarket measures of scholastic ability $\Gamma$ sum as standardized test scores. Including both test scores and schooling levels in the regression leads to a decline in the measured effect of schooling. Nevertheless $\Gamma$ scholastic test scores are imperfect measures of earning ability $\Gamma$ and these measures leave substantial scope for bias from other unobserved components of ability.

\footnotetext{
${ }^{2}$ Shea studies extracts from the Panel Study of Income Dynamics $\Gamma$ and finds no effects in the full sample. He finds modest evidence of a relationship in the low-income subsample. This finding is not inconsistent with Cameron and Heckman's (2000) interpretation that family income effects operate at the earliest stages of schooling.
} 
To correct for ability bias Tresearchers have used instrumental variables techniques to recover returns to schooling purged of bias. Anomalously $\Gamma$ instrumertal variable estimates of the return to schooling have typically been found to be larger than their OLS counterparts. Lang (1993) and Card (1995a) explore borrowing constraints as one of several possible explanations for this pattern $\Gamma$ whit Lang terms "discount-rate bias." If returns to schooling vary across individuals because of differential access to credit for educational investments $\Gamma$ the pattern of estimates produced by instrumental variables estimators may be explained by the fact that many of these estimators identify the causal effect of schooling for borrowingconstrained individuals who receive returns to schooling at the margin that are higher than the population average.

Much recent work uses instrumental variables or related techniques to address the problems caused by omitted ability measures. Card (2000) provides an extensive survey of this literature. Contrary to the intuition of ability bias $\Gamma$ he documents that researchers often find that the coefficient on schooling rises rather than falls when instrumental procedures are used. Building on Becker's Woytinsky model (1972) CLang (1993) and Card (1995a) argue that "discount rate bias" is one potential explanation for this counter-intuitive result. In the standard Becker model $\Gamma$ a studert invests in schooling until her return from schooling human capital is equal to the interest rate she faces. If borrowing constrained individuals face a higher personal interest rate $\Gamma$ the model implies they will have higher returns from schooling at the margin.

If there is no heterogeneity in the returns to schooling $\Gamma$ instrumental variables provides a consistent estimate of the return. However $\Gamma$ if there is heterogeneity in returns $\Gamma$ then the IV estimate of the causal effect of schooling must be interpreted with care. Essentially $\Gamma$ this story follows the logic of "local average treatment effects" exposited by Imbens and Angrist (1992). They show that IV measures the treatment effect of schooling (that is $\Gamma$ the causal effect) for groups whose schooling decisions are most sensitive to changes in the instrument used in estimation. Suppose that borrowing constrained individuals are most sensitive in their schooling choices to changes in $\Gamma$ say $\Gamma$ college tuition. Because of their higher costs of borrowing funds for schooling costs $\Gamma$ borrowing constrained individuals also demand the highest returns to continue. Thus $\Gamma$ the $\mathrm{IV}$ estimate of schooling returns will be an average 
of returns for this group and will be higher than the true population average of returns. ${ }^{3}$

This argument may also explain estimates obtained from studies of "selection" models of schooling $\Gamma$ which have focused on taking account of ability bias and not discount rate bias. These studies often find lower estimated returns to education in selection-corrected models (see $\Gamma$ for instance $\Gamma$ Willis and Rosen $\Gamma 1979 \Gamma$ or Taber $\Gamma 1999$ ). The argument for discount rate bias would not necessarily apply in these cases.

\subsection{Basic Methodology}

This paper takes both the returns to education literature and schooling determinants literature a step further. The hypothesis that borrowing constraints affect educational choice cannot be separated from other mechanisms in a study of returns alone or a study of schooling attainment that does not explicitly account for returns. This paper develops a structural model of schooling choice that nests both returns and school choices and allows us to estimate the importance of borrowing constraints.

Returns to education are assumed to be heterogeneous. We introduce two types of exclusion restrictions for college costs-one for foregone earnings and one for direct college costs. A rise in the direct cost of college is more costly for borrowing constrained individuals $\Gamma$ so when we relax these costs the individuals who are induced to attend college are more likely to be borrowing constrained. Thus we may suspect that when we use this type of exclusion restriction the measured returns to schooling will increase. On the other hand if we examine the opportunity cost of school (i.e. foregone earnings) $\Gamma$ there is no particular reason to expect these to be more important for borrowing constrained individuals than others. We use both instrumental variables methods and structural estimates to measure the extent of borrowing constraints. We prove that these two exclusion restrictions are enough to identify the influence of borrowing constraints.

We use these different sources of variation in costs to examine the effects of borrowing constraints on the returns to schooling using four econometric methods. (1) We use each type of cost as an instrumental variable and examine the differential impact on the returns

\footnotetext{
${ }^{3}$ Heckman and Vytlacil (1998) present a more complete description of the econometrics behind Card's (1995a) model. Angrist and Krueger (2000) also embody the idea of discount rate bias into their econometric framework.
} 
to schooling. Since direct costs of schooling affect borrowing constrained individuals more strongly we may expect that instrumenting for schooling using these costs will lead to IV estimates of the returns to schooling that are higher than OLS. On the other hand $\Gamma$ there is no particular reason to expect much discount rate bias when we use foregone income as an instrumental variable. If the ability bias dominates in this case $\Gamma$ the coefficient on IV would actually be lower than OLS. While one cannot tell with certainty which direction the bias in each case will gorIV models based on the direct costs of schooling should lead to a higher estimate of the return to schooling than with foregone earnings. (2) The story above relies on interactions between access to credit and costs of schooling. We can look for borrowing constraints directly by examining interactions between costs and observables that are likely to be related to borrowing constraints. (3) We then develop a structural version of the model and test more formally for evidence of borrowing constraints. We show that the identification of the different interest rates comes through the type of interaction between costs and observables as in the previous method. We show how the structural model generalizes standard schooling attainment models. Schooling attainment models cannot separate the influence of relative wages and other factors on schooling choices. (4) Finally we combine the methods using the structural model to look more formally for unobserved heterogeneity in credit constraints. The basic intuition for identification is that as a result of the interaction $\Gamma$ direct costs of schooling are a relatively more important determinant of schooling for individuals who face credit constraints. Thus the form of selection bias will be different for individuals who face different direct costs.

We follow Card (1995b) by using an indicator for whether there is a two- or four-year college in the individual's county as a measure of the direct costs of schooling. For students from families with low and moderate incomes $\Gamma$ the ability to live at home while in college may lead to substantial savings. The data reveal that the probability of living at home while in college is about $55 \%$ for students with a college in their county $\Gamma$ and only $34 \%$ for others. Further $\Gamma$ even for students living on campus the transportation costs and the convenience of having parents close at hand may lead to a substantial financial advantage. As a measure of the foregone earnings of schooling $\Gamma$ use measures of income in low skill industries in the county of residence. 


\section{The Model}

The model begins with a specification of individual utility. Individuals derive utility from consumption and tastes for nonpecuniary aspects of schooling. These tastes represent both the utility or disutility from school itself as well as preferences for the menu of jobs available to individuals at different levels of schooling. Assuming agents have power utility over consumption in each period $\Gamma$ lifetime utilit for a given level of schooling $S$ is given by

$$
V_{s}=\sum_{t=0}^{\infty} \delta^{t} \frac{c_{t}^{\gamma}}{\gamma}+T(S),
$$

where $c_{t}$ is consumption at time $t \Gamma T(S)$ represents tastes for schooling level $S \Gamma \delta$ is the subjective rate of time preference $\Gamma$ and $\gamma$ is a parameter of utility curvature with a value in $(-\infty, 1)$. Defining the set of possible schooling choices by $\mathcal{S}$ Tindividuals choose $S$ out of this set so that

$$
S=\arg \max \left\{V_{S} \mid S \in \mathcal{S}\right\}
$$

Much of the schooling literature $\Gamma$ including Becker (1972) $\Gamma$ Rosen (1977) $\Gamma$ Willis and Rosen (1979) $\Gamma$ Willis (1986) $\Gamma$ Lang(1994) and Card (1995) $\Gamma$ captures heterogengitin credit access by differences in the rate of interest $r$ at which a person can borrow and save throughout life. A credit constrained person faces a high $r \Gamma$ which means educational financing is more costly. An unattractive feature of this approach is that high $r$ also implies high returns to savings after labor market entry. This unattractive feature of the model can have important implications. ${ }^{4}$ We adopt the simple but novel assumption that individuals borrow at different rates while in school but face a common market interest rate for all borrowing and lending once they enter the labor market. The market rate is normalized for convenience such that $(1+r)^{-1}=\delta$. Confining borrowing-rate heterogeneity to the schooling years is a natural assumption if one considers the borrowing rate to be determined by the ability to collateralize loans with personal or family assets during school.

\footnotetext{
${ }^{4}$ For example assuming that a single $r$ prevails throughout a persons lifetime gives rise to a separation result. Given $r \Gamma$ individuals hoose schooling to maximize the present value of lifetime earnings. Thus $\Gamma$ in the standard model $\Gamma$ holding the irterest effect fixed and ignoring nonpecuniary tastes $\Gamma$ family income has no effect on schooling. In our setup an increase in parental income transfers to children raises the value of further schooling.
} 
Letting $R=1+r \Gamma$ students maximize utility subject to the budget constraint $\Gamma$

$$
\sum_{t=0}^{S-1}\left(\frac{1}{R}\right)^{t} c_{t}+\left(\frac{1}{R}\right)^{S} \sum_{t=S}^{\infty} \delta^{t-s} c_{t} \leq I_{s},
$$

where $S$ is total years of school and $I_{s}$ is the present value of income net of direct schooling costs. The first-order conditions of this problem are $\Gamma$

$$
\begin{array}{lll}
c_{t}=(\delta R)^{\frac{t}{1-\gamma}} c_{0} & t \leq S, \\
c_{t}=(\delta R)^{\frac{s}{1-\gamma}} c_{0} & t>S .
\end{array}
$$

Plugging these levels into the budget constraint yields

$$
I_{S}=\sum_{t=0}^{S-1} R^{\frac{t_{\gamma}}{1-\gamma}} \delta^{\frac{t}{1-\gamma}} c_{0}+(R \delta)^{\frac{S_{\gamma}}{1-\gamma}} \sum_{t=S}^{\infty} \delta^{t} c_{0} .
$$

Finally $\Gamma$ solving $c_{t}$ in terms of $I_{S}$ and plugging into the utility function leaves us with the following expression for lifetime utility of a person choosing $S$ years of school $\Gamma$

$$
V_{S}=\frac{I_{S}^{\gamma}\left(\sum_{t=0}^{S-1} R^{\frac{t \gamma}{1-\gamma}} \delta^{\frac{t}{1-\gamma}}+(R \delta)^{\frac{S_{\gamma}}{1-\gamma}} \sum_{t=S}^{\infty} \delta^{t}\right)^{1-\gamma}}{\gamma}+T(S) .
$$

Equation (4) is a conditional indirect lifetime utility function as it depends on the choice variable $S .{ }^{5}$

We next solve for the present value of income. To focus on borrowing constraints and abstract away from uncertain earnings we assume full certainty of earnings streams. ${ }^{6}$ Let $w_{t s}$ be earnings at time $t$ for an individual with $S$ years of schooling. Individuals have zero earnings while in school and pay tuition $\tau_{t}$ at time $t-1$ to attend schooling level $t$. Abstracting from labor supply we have the following expression for the present value of income at $t=0$ :

$$
\begin{aligned}
I_{S} & =\left(\frac{1}{R}\right)^{S} \sum_{t=S}^{T} \delta^{t-S} w_{t s}-\sum_{t=0}^{S-1}\left(\frac{1}{R}\right)^{t} \tau_{t+1} \\
& =\left(\frac{1}{R}\right)^{S} W_{S}-\sum_{t=0}^{S-1}\left(\frac{1}{R}\right)^{t} \tau_{t+1},
\end{aligned}
$$

\footnotetext{
${ }^{5}$ It may seem surprising that a rise in $R$ raises $V_{S}$. Holding $S$ fixed $\Gamma$ a rise in $R$ lowers both the present value of earnings $\Gamma I_{S} \Gamma$ and the present value of consumption expenditures. In the derivation above $\Gamma I_{S}$ is fixed $\Gamma$ so a rise in $R$ means consumption expenditures must rise so its present value stays on par with $I_{S}$.

${ }^{6}$ Uncertainty in the returns to education introduces an option value to further education even when predicted returns are low.
} 
where $W_{S}$ is the present value of earnings for schooling level $S$ discounted to time $S$.

To illustrate the implications of the model $\Gamma$ consider how changes in direct costs and opportunity costs affect schooling choices and their returns in a simple version with only two levels of schooling $\Gamma S=0$ and $S=1$. Let $\tau_{1}$ be the direct cost of $S=1 \Gamma$ and assume there are no nonpecuniary tastes for education and no direct cost of $S=0$. Values of $S=0$ and $S=1$ are given by

$$
\begin{aligned}
V_{0} & =\frac{W_{0}^{\gamma}\left(\frac{1}{1-\delta}\right)^{1-\gamma}}{\gamma} \\
V_{1} & =\frac{\left(W_{1} / R-\tau_{1}\right)^{\gamma}\left(1+(R \delta)^{\frac{\gamma}{1-\gamma}} \sum_{t=1}^{\infty} \delta^{t}\right)^{1-\gamma}}{\gamma}
\end{aligned}
$$

A person chooses $S=1$ when $D \equiv V_{1}-V_{0}>0$ and $S=0$ otherwise.

Consider two individuals indifferent between attending and not attending school (that is $\left.\Gamma V_{0}=V_{1}\right)$. One person borrows at the market rate $(R=1 / \delta)$; the other is credit constrained and borrows at $R>1 / \delta$. Consider each person's reaction at time zero to a dollar increase in foregone earnings $\Gamma W_{0} \Gamma$ and alternatiely to a dollar increase in $\tau_{1}$. For the person borrowing at the market rate $\Gamma$ a dollar is a dollar: $V_{0}=V_{1}$ implies $W_{0}=W_{1} / \delta-\tau_{1}$ and a dollar rise in $W_{0}$ and a dollar rise in $\tau_{1}$ have the same effect on the relative value of $S=1$ :

$$
-\frac{\partial D}{\partial \tau_{1}}=\frac{\gamma V_{1}}{\left(\delta W_{1}-\tau_{1}\right)}=\frac{\gamma V_{0}}{W_{0}}=\frac{\partial D}{\partial W_{0}}
$$

For the credit constrained student to be indifferent it must be that $W_{0}>\frac{1}{R} W_{1}-\tau_{1}$. This implies the shadow value of a dollar during school is higher than after labor force entry:

$$
-\frac{\partial D}{\partial \tau_{1}}=\frac{\gamma V_{1}}{\left(\frac{1}{R} W_{1}-\tau_{1}\right)}>\frac{\gamma V_{0}}{W_{0}}=\frac{\partial D}{\partial W_{0}} .
$$

More generally if the constrained and unconstrained students have identical values of $W_{0}$ and the same utility functions (that is $\Gamma \gamma$ is the same) $\Gamma$ then (6) and (7) imply the effect on $D$ of a dollar rise in foregone earnings is the same for both persons $\mathrm{Cbut}$ a dollar rise in $\tau_{1}$ reduces $D$ more for the credit-constrained student: 


$$
-\left.\frac{\partial D}{\partial \tau_{1}}\right|_{R>1 / \delta}>-\left.\frac{\partial D}{\partial \tau_{1}}\right|_{R=1 / \delta}
$$

Because the cost of attending school is higher for credit constrained students $\Gamma$ it follows in turn that credit-constrained individuals choose $S=1$ only when they receive higher returns to schooling than the marginal person borrowing at the market rate.

The main testable implications of the model can be stated more generally. Note first that a rise in $R$ reduces the likelihood a person chooses $S=1$ as long as she is not a net saver while in school: ${ }^{7}$

$$
\frac{\partial D}{\partial R}=-\frac{\gamma V_{1}}{R I_{1}}\left(c_{0}+\tau_{1}\right)<0
$$

where $c_{0}$ is optimal time 0 consumption.

First $\Gamma$ the borrowing rate $\Gamma R$ Tinfluences the schooling decisions through its interaction with direct costs $\tau_{1}$ in $V_{1}$. A dollar rise in $\tau_{1}$ diminishes the value of $V_{1}$ more for individuals with higher $R$. Thus $\Gamma$ given that a person is not a net saver during school $\Gamma$

$$
\frac{\partial^{2} D}{\partial R \partial \tau_{1}}=-\frac{\gamma V_{1}}{R I_{1}^{2}}\left[\left(c_{0}+\tau_{1}\right)(1-\gamma)+c_{0}(R \delta)^{\frac{\gamma}{1-\gamma}} \frac{\delta}{1-\delta}\right]<0
$$

Second $\Gamma$ opportunity costs $\Gamma W_{0}$, operate only through $V_{0} \Gamma$ so there is no interaction with $R$. Hence $\Gamma$ a drange in $W_{0}$ has the same influence on the schooling decisions of the constrained and unconstrained student:

$$
\frac{\partial^{2} D}{\partial R \partial W_{0}}=0
$$

Third $\Gamma$ the return to education for borrowing constrained persons is higher than it is for unconstrained and otherwise identical individuals.

For studying returns to schooling using an instrumental variables (IV) framework $\Gamma$ both the schooling choice $S$ and the returns to $S$ a person receives depend on $R$. In the population $\Gamma$ returns to shooling is a random variable rather than a one-dimensional parameter. Imbens and Angrist (1992) show in this situation that IV recovers the average return on schooling for the subset of the population that is induced to change status by the change

\footnotetext{
${ }^{7}$ This is true as long as $c_{0}>-\tau_{1}$ and always true as long as schooling costs are positive.
} 
in the instrument. ${ }^{8}$ More specifically $\Gamma$ when one instrumerts for school choice using college costs $\Gamma$ IV estimates recover the average return to college for the group of individuals who attend college only when college costs are low. The model above implies that the group that is induced to change will depend on whether it is the opportunity cost or direct costs of schooling that fall. Since direct costs have a relatively large effect on borrowing constrained students $\Gamma$ the group that changes with direct costs should have a higher concentration of borrowing constrained students. Among those students close to indifference about attending college $\Gamma$ individuals with higher interest rates will average higher returns to college. Thus $\Gamma$ an IV estimate of the returns to shooling should be higher when endogenous schooling is instrumented with direct costs than with opportunity costs. Using the language of Lang(1993) and Card (1996) the "discount rate bias" will be higher when direct costs are used as an instrument relative to when opportunity costs are used.

While it is intuitively appealing and suggestive $\Gamma$ this argument is not precise since the actual coefficient on schooling depends on the full joint distribution of variables close to the margin and depends on the other regressors. The structural model below uses this same basic idea for identification $\Gamma$ butjustifies it formally.

\section{The Data}

Our analysis is based on Black $\Gamma$ Hispanic $\Gamma$ and White males from the 1979-1994 waves of the NLSY (National Longitudinal Survey of Youth). We exclude from the analysis the military subsample and the non-Black non-Hispanic disadvantaged sample. We use only male samples because their schooling decisions and labor supply are less complicated by fertility and labor market participation considerations.

Because the NLSY collected detailed information about school attendance and completion starting from January of 1978 it is ideal for our study. Schooling observations begin at age 15 and extend at least through age 29 for all individuals included in our sample. Because information before 1978 is retrospective and limited $\Gamma$ we confine our extract to males between age 13 and 17 in January of 1978 in order to have reliable information on

\footnotetext{
${ }^{8}$ In the language of Imbens and Angrist (1992) $\Gamma$ instrumental variables estimators converge to the expected treatment effect for those individuals induced to change status by the change in the instrument. In our model the treatment is school and the treatment effect is the returns to schooling.
} 
parental income and county of residence $\Gamma$ which is used to construct a number of measures of labor market conditions and college proximity.

Instruments for foregone earnings are created from county-level labor market measures taken from Bureau of Economic Analysis (BEA) data merged with NLSY countyof-residence identifiers. Opportunity cost of schooling is proxied by average local earnings ("local" is defined as the county of residence) in industries overrepresented by unskilled workers. Since the BEA data are reported by industry and not occupation $\Gamma$ use average earnings per job in service $\Gamma$ agriculture $\Gamma$ and thewholesale and retail trade industries. One large component of these industries is retail food establishments. For transitions into college $\Gamma$ the set of industries for whit average wages is constructed includes the aforementioned set together with manufacturing $\Gamma$ construction $\Gamma$ mining and extraction $\Gamma$ and transportation and public utilities.

College costs are instrumented with identifiers for the presence of two-year and fouryear colleges in the county of residence at age 17. College identifiers were extracted from the Department of Education's annual HEGIS and IPEDS "Institutional Characteristics" surveys. From this data we were able to determine the presence of a two-year college $\Gamma$ a four-year college $\Gamma$ or either in the county of residence. A number of specialty colleges $\Gamma$ generally with small enrollments less than $100 \Gamma$ were excluded. Federal institutions $\Gamma$ such as the Naval Academy $\Gamma$ were also excluded. This variables can be measured at any age. For our analysis $\Gamma$ however $\Gamma$ they are measured at age 17 to avoid the obvious problem that people who attend college generally reside in the same county the college is located. We present summary statistics of the main variables used in the analysis in Table 1.

\section{$5 \quad$ Regression and Instrumental Variable Results}

\subsection{Methodological Issues}

Our first empirical goal is to use the instrumental variables approach discussed above using the two costs of schooling as exclusion restrictions. There are a few problems that arise in implementation of our approach. The first potential problem is that since high school graduates leave school earlier $\Gamma$ our data conain more observations on high school graduates 
than college graduates. We solve this problem by focusing on men of age 22 and older. ${ }^{9}$

The second problem arises in the use of the local labor market variables. Our goal is to use the opportunity cost of college as an instrumental variable. We measure this by using income in the county that the student lived at age 17. A problem with this variable is that labor market variables at age $\mathbf{1 7}$ are likely to be correlated with local labor market variables later in life. To deal with this potential problem we include a measure of the local income in the wage regression itself $\Gamma$

$$
\log \left(w_{i t}\right)=\beta_{0}+S_{i} \beta_{1}+\ell_{i t} \beta_{2}+X_{i t} \beta_{3}+u_{i t}
$$

where $w_{i t}$ is the hourly wage $\Gamma S_{i}$ is schooling $\Gamma$ and $\ell_{i t}$ is a measure of the local income in the county in which individual $i$ lives at time $t$. This seems to potentially solve the problem since it is reasonable to believe that conditional on current labor market conditions $\Gamma$ the local labor market conditions at age 17 are unrelated to earnings directly.

The use of this variable leads to an additional potential problem. Moving is endogenous and is related to schooling outcomes $\Gamma$ particularly for college. If this is the case $\Gamma \ell_{i t}$ is also endogenous. A natural instrument in this case is the local income rate at time $t$ in the county in which $i$ lived at age 17 . Since many individuals do not switch counties $\Gamma$ or do not move far when they do $\Gamma$ this instrument is strongly correlated with local income at $t$. Secondly $\Gamma$ since it is determined by the county in which the student lives at age $17 \Gamma$ it does not depend on moving after schooling completion so is not endogenous.

A third potential problem is the endogeneity of experience. We assume that experience is equal to age minus education minus six. However $\Gamma$ as other authors have pointed out $\Gamma$ if education is endogenous $\Gamma$ then experience is endogenous as well. We instrument for experience and experience squared using age and age squared in some of our specifications.

\subsection{First Stage Results}

In this model the first stage regression is not particularly meaningful. Since we have more than one observation per individual in the wage data $\Gamma$ we also have more than one observation per individual in the first stage. Secondly $\Gamma$ since the dependent variable $\Gamma$ schooling $\Gamma$

\footnotetext{
${ }^{9}$ We have experimented with higher age cutoffs and find that the basic results are not sensitive to this choice.
} 
does not vary $\Gamma$ but the local income measure does the regression is hard to interpret. In an attempt to convey the content of the first stage regressions we construct the average of the local income variable in the county at age 17 across the years in which the respondent works. We then regress schooling on our standard variables as well as this average $\Gamma$ the local income at age $17 \Gamma$ and theindicator for whether there is a college in the county. The results of these regressions are reported in Table 2.

In Column (1) we present the regression of schooling on a number of covariates including the dummy variable for a college in the county. This effect of this variable is large implying that individuals with a college in their county complete almost one half year more of school on average. The other covariates in the regression have signs and magnitudes similar to other work (see e.g. Cameron and Heckman $\Gamma$ 2000). In column (2) we present results where we include the local income variable at age 17 in the regression. It has the expected sign $\Gamma$ but is not significant. However $\Gamma$ in column (3) we control for the mean local income over working life. The results here are as expected. The coefficient on this new variable is positive indicating that richer counties are likely to have more students attend college. ${ }^{\mathbf{1 0}}$ This leads the coefficient on the opportunity cost of school to be negative as expected. There are two potential explanations of this result $\Gamma$ both of which seem to be important for the result. First individuals could be more likely to attend school during temporary downturns. Second individuals in counties in which the economy is improving could be more likely to attend college. In terms of the model above $\Gamma$ we would expect both of these effects to influence schooling $\Gamma$ and it is not importan which. Intuitively $\Gamma$ the first possibilit is perhaps more appealing as a source of identification since it does not seem to embed essential features of the county itself. However $\Gamma$ we will present some evidence below that we do not see a pattern when we look at observable ability measures $\Gamma$ so it seems plausible that it isn't related to unobservable ability differences. In the final column we combine the two variables and show that both remain strong predictors.

\footnotetext{
${ }^{10}$ Perhaps as a result of superior schools or peer effects.
} 


\subsection{Excluding Foregone Earnings}

We first examine the returns to schooling when we use the local labor market variable as an instrument in Table 3 . Given that this variable does not necessarily have a larger impact on borrowing constrained individuals $\Gamma$ we would not particularly expect the coefficient on schooling to increase when we use it as an instrumental variable. However $\Gamma$ we see in the first three columns that the IV point estimate is substantially above the OLS estimate. One should keep in mind that the standard errors are large enough so that we cannot reject the hypothesis that the OLS estimates and the IV estimates are the same. In columns 4-6 we perform the same exercise but do not include test scores and family income in the model. The point estimates are higher in this case $\mathrm{b}$ but the pattern is quite similar. In experimenting with other specifications we see similar patterns. These results are similar to Arkes (1998) who uses state unemployment rates in a similar design and also finds IV estimates that are higher than the OLS estimates.

This result that the coefficients increase when excluding foregone earnings is not necessarily inconsistent with the notion of discount rate bias above. It may happen to be that the people at the margin tend to be borrowing constrained and that their marginal return exceeds the OLS estimate. If this were the case $\Gamma$ then we would expect the coefficient to increase even more when we use the presence of a college as an instrument.

One potential problem with the model above in addressing schooling decisions during recessions is that there is no role for the family. In this case it may be that when local labor market conditions are poor $\Gamma$ borrowing constrained families have more trouble sending their children to college. This would reverse the direction of the effect; schooling would increase during a boom particularly for children whose parents are borrowing constrained. If we incorporated this possibility into our model $\Gamma$ the effects of local labor market conditions on schooling attendance would no longer be monotonic. We might expect borrowing constrained families to be more likely to send their children to college during a boom $\Gamma$ while non-borrowing constrained families would be less likely (as a result of the foregone earnings). Given that we find a negative association between county income and schooling $\Gamma$ this second effect appears to dominate. This makes these results perhaps more surprising. Suppose borrowing constrained families have higher marginal returns to schooling and that 
the students from these families are led to decrease schooling during a recession. This effect should lead to smaller values of the IV estimate. The fact that the IV estimate is higher than the OLS estimate appears even more counterintuitive if credit constraints were important. We formalize this argument in the Appendix $\Gamma$ section A.

\subsection{Excluding Direct Costs of Schooling}

The results using presence of a local college are presented in Tables $4 \mathrm{a}$ and $4 \mathrm{~b}$. The first three columns present results that do not control for the local income variable. These estimates yield very large effects of the causal effect of schooling. However $\Gamma$ controlling for the local income variable yields striking results. The estimates of the returns to schooling decline enormously so that they are very similar in magnitude to the OLS results. In Table $4 \mathrm{~b}$ we present additional specifications. In the first set of results we control for the AFQT score from the NLSY instead of the four test scores. These give IV estimates that are substantially lower than OLS. When we include no controls for test scores or family income we get results similar to the last three columns of Table $5 \mathrm{a}$. The fact that the results decline so much when we control for the local wages indicate that presence of a college seems to be positively correlated with wealth in the county. Most importantly $\Gamma$ theIV point estimates are not higher than the OLS estimates.

Combining the results from the two tables we see the opposite of what the borrowing constrained model predicts. Instrumenting with measures of direct costs of college rather than the opportunity cost does not lead to higher estimates of the returns to college. Thus we find no evidence that discount rate bias is important in this exercise.

\subsection{Validity of the Instruments}

In general $\Gamma$ without a maintained assumption that one of our instruments is valid $\Gamma$ it is impossible to test them. In addition $\Gamma$ since we allow the treatment effect to be random $\Gamma a$ standard over-identification test will not work. However $\Gamma$ it is often informative to examine the relationship between the excluded variables and the observables in the wage equation. While the lack of a relationship between observable measures of ability and the instruments does not prove that there is no relationship between unobservable measures of ability and 
them $\Gamma$ itdoes lend some credence to their use.

In Table 5 we present regressions of the two instruments on various observables. The dummy variable for presence of a college in the county is the dependent variable in the first column. The results in this regression are somewhat discouraging. The math score from the ASVAB test does seem to be positively related to whether there is a college in the county. Given the importance of this variable in both the schooling equation and the wage equation $\Gamma$ this seems potentially problematic. Fathers education and the automotive knowledge score also are related to this instrument. This result makes our finding even more surprising. Presence of a college seems to be positively correlated with observable ability. If it were positively correlated with unobservable ability as well then the schooling estimate is biased upwards. ${ }^{11}$ The good news however is that conditional on the average wage during working life $\Gamma$ test scores do not help predict the local labor market variable at age 17. These results are shown in the second column of Table 5. While certainly not conclusive $\Gamma$ this result is favorable to the use of the local labor market variation as an instrument.

The fact that test scores help predict the presence of a college in the county is not necessarily problematic $\Gamma$ since we control for these variables in our regression. Table 6 presents results that are more favorable for the use of the college in county as an instrumental variable. In this table we present results from probit models of our standard set of regressors (from e.g. Table 2) on college attendance and high school dropout status. If the college in county variable is exogenous it should have a much stronger effect on college attendance than dropping out of high school. ${ }^{12}$ However $\Gamma$ if college in county is picking up "pro-schooling" aspects of the community rather than just the reduction in the cost of college $\Gamma$ then we would expect it to predict high school graduation as well. Our results in Table 6 show that presence of a college in the county has a large effect on college attendance but a statistically insignificant effect on high school graduation. While the point estimate of the dropout effect is not zero $\Gamma$ these results seem to suggest that the instrumert is affecting school choice as we would have expected. Again while this is not conclusive $\Gamma$

\footnotetext{
${ }^{11}$ Altonji $\Gamma$ Elder $\Gamma$ and aber (2000) provide a model that justifies this type of argument.

${ }^{12}$ It should have some effect on high school dropout status by changing the option value of high school graduation.
} 
it does suggest that the instrument is working in the manner we would expect if it were a valid instrument.

\subsection{Interactions between Observables and Direct Costs}

The argument about identification above relied on the relationship between access to credit and the direct costs of schooling. We used the model to show that the direct costs of schooling place a larger burden for individuals who are credit constrained. If we could observe individuals in the data who were credit constrained we could test this directly since we expect the presence of a college in their county to have a larger impact on their schooling decisions. While we cannot observe credit constraints directly $\Gamma$ we can observe some variables that we would expect to be related. In particular we can look for interactions between the presence of a college and race $\Gamma$ family bakground $\Gamma$ and family income ariables. Card (1995b) and Kling (1999) also look for these interactions in the National Longitudinal Survey of Young Men and show that individuals from low family background are affected more by the presence of a college. Our results are different.

In Table 7 we present the results of schooling regressed on our standard set of covariates and interactions between the presence of a college and different variable. The first column interacts the dummy variable with racial dummies for black and Hispanic. Since it is well known that blacks tend to have less wealth for the same amount of income $\Gamma$ it migh make sense to expect blacks to be credit constrained. In fact we find that the interaction is negative showing that the presence of a college seems to be more important for whites than for blacks (although it is statistically insignificant). The sign on the Hispanic interaction is also the opposite of what we would expect if they had less access to credit. In the second column we interact the dummy variable with parents education. In this case the interaction with father's education is positive and the interaction with mother's education is negative. It is hard to interpret this as evidence of credit constraints. In the next two columns we present the results for family income and number of siblings. Once again the interactions are insignificant and of the wrong sign. We see essentially no evidence of credit constraints in this table.

There are a number of reasons why our results may differ from Card (1995b). Perhaps the largest difference is that our cohorts are much younger than theirs. Our results are 
consistent with the idea that credit constraints may have been important when the NLS Young Men were making their schooling decisions in the 1960 's $\Gamma$ but much less important when the NLS Youth were making their decisions in the early 1980s. Of course $\Gamma$ the data sets differ in a number of other ways so this may not be the explanation. Discovering whether this is actually the case is an important avenue for future research. ${ }^{13}$

\section{Evidence From The Structural Model}

\subsection{The Econometric Model}

In this section we extend the model above into a specific econometric framework which we take directly to the data. Let wages for person $i$ take the form $\Gamma$

$$
\log \left(w_{s i t}\right)=\gamma_{S}+X_{W i}^{\prime} \beta_{W}+X_{\ell i t}^{\prime} \beta_{\ell}+e_{i t} \beta_{e}+e_{i t}^{2} \beta_{e^{2}}+u_{s i t}
$$

where $e_{i t}$ is experience $\Gamma X_{\ell i t}$ consists of local labor market variables at time $t \Gamma X_{W i}$ is a vector of non-time varying variables that influence wages $\Gamma$ and $u_{s i t}$ represents an error term orthogonal to the observed covariates. Wage effects are captured through a level effect $\gamma_{S}$ and a schooling-specific $\Gamma$ person-specific series of shocks $\left\{u_{s i t}\right\}$. If individual $i$ chooses schooling level $S \Gamma$ his present value of earnings dated at the time he leaves school is $\Gamma$

$$
\sum_{t=S}^{\infty} \delta^{t-S} e^{\gamma_{S}+X_{W i}^{\prime} \beta_{W}+X_{t i t} \beta_{\ell}+e_{i t} \beta_{e}+e_{i t}^{2} \beta_{e^{2}}+u_{s i t}} .
$$

Until a person enters the labor market $\Gamma$ he has partial information about the stream of shocks $\left\{u_{s i t}\right\}$. Once in the market $\Gamma$ a person with schooling level $S$ observes the shock $u_{s i t^{\prime}}$ at time period $t^{\prime}$. Abstracting from uncertainty about the shocks $\left\{u_{s i t}\right\} \Gamma$ we assume students choose schooling to solve the certainty equivalence problem. Let $E_{0}$ denote wage

\footnotetext{
${ }^{13}$ In results not reported in the version of his paper that we citer Kling also ran regressions using NLSY data. In contrast to us he found results similar to Card in a relationship between poor family background and schooling. Kling kindly provided us with the code he used to generate his data and we attempted to uncover the difference. Even though the variables we used were very similar $\Gamma$ the difference in the results seem to come from both the differences in the definition of college in county and the fact that we are using a younger sample. Both Card (1995b) and Kling(1997) focus on parents education in these interactions. When we used Kling's variable and interact it with race $\Gamma$ nmber of siblings $\Gamma$ and family income as in our specification we get found no interactions (except for race which goes in the unexpected direction as in our results). We also repeated our IV estimates described above using Kling's measure of presence of a college. It yields point estimates that are very close $\Gamma$ but with substantially higher standard errors.
} 
expectations at time zero when schooling decisions are made. Decisions are made based on the expected present value of income $\Gamma$

$$
I_{S i}=\left(\frac{1}{R_{i}}\right)^{S} e^{\gamma_{S}+X_{W i}^{\prime} \beta_{W}}\left(\sum_{t=S}^{\infty} \delta^{t-S} e^{e_{i t} \beta_{e}+e_{i t}^{2} \beta_{e^{2}}+E_{0}\left(x_{t i t}^{\prime} \beta_{\ell}\right)+E_{0}\left(u_{i t}\right)}\right)-\sum_{t=0}^{S-1}\left(\frac{1}{R_{i}}\right)^{t} X_{i c}^{\prime} \beta_{c}
$$

where $R_{i}$ represents the individual borrowing rate $\Gamma$ which is discussed below $\Gamma$ and costs of schooling $\left(\tau_{t}\right)$ are parameterized to depend on observables as $X_{i c}^{\prime} \beta_{c}{ }^{14}$

For empirical implementation $\Gamma$ we further simplify the model in three ways. First $\Gamma$ we assume that $u_{s i t}=\theta_{s i}+\omega_{i t}$ where $\theta_{s i}$ is a person-specific $\Gamma$ time-invariant component of the error term known to the student when schooling decisions are made but not observed by the econometrician. The component $\omega_{i t}$ is orthogonal to time 0 information $\Gamma \operatorname{so} \theta_{s i}=E_{0}\left(u_{s i t}\right)$. Second $\Gamma$ we approximate $E_{0}\left(X_{\ell i t}^{\prime} \beta_{\ell}\right)$ by a linear function of local labor market variables known to the students when schooling decisions are made. Denote these variables by $X_{\ell s i}$ with coefficient vector $\widetilde{\beta}_{\ell S}$. To simplify the notation we incorporate the intercept $\gamma_{S}$ into $\widetilde{\beta}_{\ell S}$ so that $\Gamma$

$$
X_{\ell s i}^{\prime} \widetilde{\beta}_{\ell S}=E_{0}\left(X_{\ell i t}^{\prime} \beta_{\ell}\right)+\gamma_{S}+\log \left(\sum_{t=S}^{\infty} \delta^{t-S} e^{e_{i t} \beta_{E}+e_{i t}^{2} \beta_{E^{2}}}\right)
$$

Finally we simplify the model by using $\log$ utility. ${ }^{15}$ Solving for the value of $S$ under $\log$ utility $\Gamma$ and plugging $I_{S i}$ from above yields $\Gamma$

$$
\begin{aligned}
V_{S i}= & \left(\frac{1}{1-\delta}\right)\left(\log \left(I_{S i}\right)+\log (1-\delta)\right)+\left[\sum_{t=0}^{S-1} \delta^{t} t+\left(\frac{\delta^{S+1}}{1-\delta}\right) S\right] \log \left(\delta R_{i}\right)+X_{T i}^{\prime} \beta_{T S}+\nu_{s i} \\
= & \alpha_{1} \log \left(\left(\frac{1}{R_{i}}\right)^{S} e^{X_{W i}^{\prime} \beta_{W}+X_{t s i}^{\prime} \widetilde{\beta}_{t S}+\theta_{s i}}-\sum_{t=0}^{S}\left(\frac{1}{R_{i}}\right)^{t} X_{c i}^{\prime} \beta_{c}\right) \\
& +\alpha_{2}(S)+\alpha_{3}(S) \log \left(R_{i}\right)+X_{i T}^{\prime} \beta_{T S}+\nu_{s i},
\end{aligned}
$$

where $X_{T i}^{\prime} \beta_{T S}+\nu_{s i}$ represents the nonpecuniary benefits or costs associated with schooling level $S$. Though complicated $\Gamma$ this expression is ery close to a standard linear index model. The only nonlinearity arises from the term inside the logarithm. From this expression one

\footnotetext{
${ }^{14}$ Notice that we have assumed that costs depend only on observables. This was chosen for computational convenience $\Gamma$ but we see no reason why this should bias the findings in either direction.

${ }^{15}$ We see no reason why this should bias the results in any particular direction.
} 
can see the interaction between interest rates $R_{i}$ and costs $X_{i c}^{\prime} \beta_{c}$. There is no such interaction between interest rates and foregone earnings. This aspect of the model $\Gamma$ discussed in the theory section above $\Gamma$ delivers identification of the parameters of interest.

\subsection{Sketch of Identification}

To convey the basic mechanism by which identification is achieved $\Gamma$ begin by assuming again there are only two levels of schooling and no direct cost for level 0 . In the empirical implementation of the model $\Gamma$ shooling is divided into four levels $\Gamma$ but more le identification. The values of each level of schooling are

$$
\begin{aligned}
V_{0 i}= & \alpha_{1}\left(X_{W i}^{\prime} \beta_{W}+X_{\ell 0 i}^{\prime} \widetilde{\beta}_{\ell 0}+\theta_{0 i}\right)+a_{1} \\
& +X_{T i}^{\prime} \beta_{T 0}+\nu_{T 0 i} \\
V_{1 i}= & \alpha_{1} \log \left(e^{-\log \left(R_{i}\right)+X_{W i}^{\prime} \beta_{W}+X_{\ell 1 i}^{\prime} \tilde{\beta}_{\ell 1}+\theta_{1 i}}-X_{c i}^{\prime} \beta_{c}\right)+a_{2} \\
& +a_{3} \log \left(R_{i}\right)+X_{T i}^{\prime} \beta_{T 1}+\nu_{T 1 i} .
\end{aligned}
$$

We estimate two versions of the model. The first allows for heterogeneity in $R_{i}$ by letting it depend on particular observables such as race and family income. The second version treats $R_{i}$ as a variable unobserved by the econometrician.

To begin $\Gamma$ ve show how the model generalizes the schooling models discussed in Section 5.6. First $\Gamma$ suppose there is no unobserved heterogeneity $\left(\theta_{s i}=0\right)$ and that local labor market variables and wage variables are not determinants of schooling value (that is $\Gamma$ set $X_{W i}^{\prime} \beta_{W}+X_{\ell S i}^{\prime} \widetilde{\beta}_{\ell S}=0$ for $S=0$ and $\left.S=1\right)$. Let $R_{i}$ be parameterized by $\left(R_{i}\right)=X_{R}^{\prime} \beta_{R}$ and assume costs $\Gamma X_{c i}^{\prime} \beta_{c} \Gamma$ vary only with the presence of a college in the county. Testing for interest rate heterogeneity in this specification $\left(\beta_{R}=0\right)$ is equivalent to the test for an interaction between the presence of a college and $X_{R}$ performed for the simple regression model of Section 5.6. The main difficulty with that approach is that we had no way to parcel out the effects of wage variables and the local labor market variables on schooling decisions. With no selection in model $\Gamma \beta_{w}$ and $\widetilde{\beta}_{\ell 1}$ can be estimated from the wage equation when some assumption is made about how agents predict future local labor market variables.

Now consider the more complicated case in which $R_{i}$ is unobserved. Taking the differ- 
ence and combining the parameters yields the latent variable representation $\Gamma$

$$
\begin{aligned}
Y_{i}^{*} & =V_{1 i}-V_{0 i} \\
& =\alpha_{1} \log \left(e^{X_{i} \Gamma_{1}+\varepsilon_{1 i}}-X_{c i}^{\prime} \beta_{c}\right)+X_{i} \Gamma_{2}+\varepsilon_{2 i},
\end{aligned}
$$

where $\Gamma$

$$
\begin{aligned}
X_{i} \Gamma_{1} & =X_{W i}^{\prime} \beta_{W}+X_{\ell 1 i}^{\prime} \widetilde{\beta}_{\ell 1} \\
\varepsilon_{1 i} & =\theta_{1 i}-\log \left(R_{i}\right) \\
X_{i} \Gamma_{2} & =X_{T i}^{\prime} \beta_{T 1}-\alpha_{1}\left(X_{W i}^{\prime} \beta_{W}+X_{\ell 0 i}^{\prime} \widetilde{\beta}_{\ell 0}\right)+a_{2}-a_{1}-X_{T i}^{\prime} \beta_{T 0} \\
\varepsilon_{2 i} & =a_{3} \log \left(R_{i}\right)+\nu_{T 1 i}-\alpha_{1} \theta_{0 i}-\nu_{T 0 i} .
\end{aligned}
$$

Individuals choose schooling option 1 if $Y_{i}^{*}>0$, and choose option 0 otherwise.

Assume $\left(X_{i}, X_{c i}\right)$ is observable while $\left(\theta_{1 i}, \theta_{0 i} \log \left(R_{i}\right), u_{T 1 i}, u_{T 0 i}\right)$ is unobservable and independent of the observables. Looking at the selection equation we have essentially three indices $\Gamma$

$$
\left(X_{i} \Gamma_{1}, X_{i} \Gamma_{2}, X_{i c}^{\prime} \beta_{c}\right)
$$

and two error terms $\left(\varepsilon_{1 i}, \varepsilon_{2 i}\right)$. These three degrees of freedom allow us to trace out this joint distribution.

However $\Gamma$ the schooling equation alone is not sufficient for identification of the distribution of $R_{i}$ as one cannot separate it from $\theta_{1 i}$. Additional data on wage earnings is needed to distinguish between these error terms. We have data on wages where $\Gamma$

$$
\log \left(w_{i 1 t}\right)=\gamma_{S}+X_{i W}^{\prime} \beta_{W}+X_{i \ell t}^{\prime} \beta_{\ell}+E_{i t} \beta_{E}+E_{i t}^{2} \beta_{E^{2}}+u_{1 i}
$$

Theorem 1 in the Appendix proves nonparametric identification of the joint distribution of $\left(\varepsilon_{1 i}, \varepsilon_{2 i}, u_{1 i}\right)$ using the two types of exclusion restrictions $\Gamma$ one for wages and one for direct costs. Given this joint distribution we can identify the conditional expectation of $E\left(u_{1 i} \mid \varepsilon_{1 i}\right)=E\left(\theta_{1 i} \mid \theta_{1 i}-\log \left(R_{i}\right)\right)$. We also show in the appendix that we can use this conditional expectation to estimate the distribution of $R_{i}$ when $R_{i}$ is independent of $\theta_{1 i}$. Thus we can identify the distribution of interest rates faced by students up to a normalization that we discuss in the appendix. 
The identification result crucially depends on the fact that we have two different types of exclusion restrictions: local labor market variables that affect students school choices but not $w_{i 1 t}$, and the presence of college which influences only costs. ${ }^{16}$ This gives us essentially two degrees of freedom which allow us to trace out the two dimensional distribution $\left(\varepsilon_{1 i}, \varepsilon_{2 i}\right) \cdot{ }^{17}$ Combining this information with the wage data allows us to separate $R_{i}$ from $\theta_{1 i}-\log \left(R_{i}\right)$ since only $\theta_{1 i}$ influences wages.

The basic intuition for identification in practice comes from examining the dependence of the form of selection bias on whether there is a college in one's county or not $\Gamma$

$$
E\left(\theta_{1 i} \mid \alpha_{1} \log \left(e^{X_{i} \Gamma_{1}+\theta_{1 i}-\log \left(R_{i}\right)}-X_{c i}^{\prime} \beta_{c}\right)+X_{i} \Gamma_{2}+\varepsilon_{2 i}, X_{i} \Gamma_{1}, X_{\mathrm{c} i}^{\prime} \beta_{c}, X_{i} \Gamma_{2}\right) .
$$

In general this expression is complicated and will depend on the full joint distribution of $\left(\theta_{1 i}, R_{i}, \varepsilon_{2 i}\right)$. As an example $\Gamma$ suppose that interest rates are independent of the other error terms. Following exactly the same logic as in Section 3 above $\Gamma$ because the $\log ()$ expression is nonlinear the term $\theta_{1 i}-\log \left(R_{i}\right)$ will be relatively more important when costs of schooling are high. If borrowing constraints were not important this means that since $\theta_{1 i}$ is relatively more important when a college is costly $\Gamma$ there will be more selection bias in counties that do not contain a college. However $\Gamma$ if $R_{i}$ is relatively more important than $\theta_{1 i}$, then when costs are high schooling decisions will be dictated by the extent of borrowing constraints. This would imply that there is less selection bias when no college is present. This basic intuition is extremely close to that for identification in the Instrumental Variables model.

\subsection{Evidence from observables}

We parameterize interest rates so that $\Gamma$

$$
R_{i}=\exp \left[\exp \left(X_{R i}^{\prime} \beta_{R}+\log [-\log (\delta)]\right)\right] .
$$

where $X_{R i}$ are variables that may determine the borrowing rate. This functional form was chosen for two reasons. First $\Gamma R_{i}$ is restricted to reasonable ranges: it will be strictly greater

\footnotetext{
${ }^{16} U$ sing the notation above $\Gamma$ the first $y$ pe of exclusion restriction affects $X_{i} \Gamma_{2}$, but not $X_{i} \Gamma_{1}$ or $X_{i c}^{\prime} \beta_{c}$ and the second enters $X_{c i}^{\prime} \beta_{c}$ but not $X_{i} \Gamma_{2}$ or $X_{i} \Gamma_{1}$.

${ }^{17}$ The appendix requires full support of $X_{c i} \beta_{c}$. This is clearly not true in our data $\Gamma$ but our goal is simply to test for the presence of borrowing rate heterogeneity not to identify the full joint distribution. The goal of the formal identification section is to demonstrate the manner in which multiple types of exclusion restrictions can facilitate identification.
} 
than one but can be arbitrarily large. Second $\Gamma$ it facilitates comparison between borrowing constrained individuals and others that are not constrained. In this specification when $X_{R i}^{\prime} \beta=0, R_{i}$ is equal to the market interest rate and these individuals are not constrained. We do not include an intercept in $X_{R i}$, so we can normalize a subgroup of the population to be able to borrow and lend freely by setting the value of $X_{R i}$ to zero for those individuals. For example we will test for racial inequality in access to credit by using dummy variables. In this case $X_{R i}$ consists of only a dummy variable for black and a dummy variable for Hispanics. Thus for whites both dummy variables are zero $\Gamma$ which imposes that for them $R_{i}=\frac{1}{\delta}$.

In this section we ignore the selection problem so that in the notation above $\theta_{s i}=0$ and $\nu_{T s i}$ is independent of $u_{i t}$. We relax this restriction in the next subsection. Thus $\Gamma$ the $\beta_{W}$ parameters are estimated by OLS and the estimated values are inserted into the value function (the standard errors of the value-function parameters are adjusted appropriately). The cost index $\Gamma X_{c i}^{\prime} \beta_{c}$, consists of only the distance from college and a constant. The vector of taste variables $\Gamma X_{T i}$ contains most of the variables entering the schooling decisions as in Table 2 above. ${ }^{18}$ The local labor market variables enter the model through the index $X_{\ell s i}^{\prime} \widetilde{\beta}_{\ell S}$. We incorporate two measures of local labor markets into $X_{\ell s i}$. The first is the income at age seventeen and eighteen of the county in which the individual lived at age 17. This is restricted to affect only the earnings of high school graduates and high school dropouts. The second variable is the long run average income in the county of residence at age 17. This variable enters all four equations.

We assume that there are four levels of schooling $\Gamma$ high school dropouts $(S=0) \Gamma$ high school graduates $(S=2) \Gamma$ some college $(S=4) \Gamma$ and college graduates $(S=6)$. During high school there are no direct pecuniary costs of schooling $\Gamma$ but they must be incurred for students who attend some college and for college graduates.

We assume that $\nu_{T s i}$ has a Generalized Extreme Value distribution (GEV) so that the model can be estimated as a nested logit. We use two levels of nesting first nesting all high school graduates together and then nesting college attenders together. The observable

\footnotetext{
${ }^{18}$ The college in county indicator and the local labor market variables are not included in $X_{T i}$.
} 
components of the utilities take the form $\Gamma$

$$
\begin{aligned}
& \mu_{i 0}=\alpha_{1}\left(X_{W i}^{\prime} \beta_{W}+X_{\ell 0 i}^{\prime} \tilde{\beta}_{\ell 0}\right)+\alpha_{2}(0) \\
& \mu_{i 2}=\alpha_{1}\left(-2 \log \left(R_{i}\right)+X_{W i}^{\prime} \beta_{W}+X_{\ell 2 i}^{\prime} \widetilde{\beta}_{\ell 2}\right)+\alpha_{2}(2)+\alpha_{3}(2) \log \left(R_{i}\right)+X_{T i}^{\prime} \beta_{T 2} \\
& \mu_{i 4}=\alpha_{1} \log \left(\left(\frac{1}{R_{i}}\right)^{4} e^{X_{i W}^{\prime} \beta_{W}+X_{\ell 4 i}^{\prime} \tilde{\beta}_{\ell 4}}-\sum_{t=2}^{3}\left(\frac{1}{R_{i}}\right)^{t} X_{i c}^{\prime} \beta_{c}\right)+\alpha_{2}(4)+\alpha_{3}(4) \log \left(R_{i}\right)+X_{T i}^{\prime} \beta_{T 4} \\
& \mu_{i 6}=\alpha_{1} \log \left(\left(\frac{1}{R_{i}}\right)^{6} e^{X_{W i}^{\prime} \beta_{W}+X_{\ell \ell i}^{\prime} \tilde{\beta}_{\ell \ell}}-\sum_{t=2}^{5}\left(\frac{1}{R_{i}}\right)^{t} X_{c i}^{\prime} \beta_{c}\right)+\alpha_{2}(6)+\alpha_{3}(6) \log \left(R_{i}\right)+X_{T i}^{\prime} \beta_{T 6}
\end{aligned}
$$

The nesting yields the following schooling probabilities $\Gamma$

$$
\begin{aligned}
& \operatorname{Pr}\left(S=6 \mid S>2, \mu_{i 0, \ldots, \mu_{i 6}}\right)=\frac{\exp \left(\frac{\mu_{i 6}}{\rho_{c}}\right)}{\exp \left(\frac{\mu_{i 6}}{\rho_{c}}\right)+\exp \left(\frac{\mu_{i 4}}{\rho_{c}}\right)} \\
& \operatorname{Pr}\left(S=2 \mid S>0, \mu_{i 0, \ldots,}, \mu_{i 6}\right)=\frac{\exp \left(\frac{\mu_{i 2}}{\rho_{H}}\right)}{\exp \left(\frac{\mu_{i 2}}{\rho_{H}}\right)+\left[\exp \left(\frac{\mu_{i 4}}{\rho_{C}}\right)+\exp \left(\frac{\mu_{i 6}}{\rho_{c}}\right)\right]^{\frac{\rho_{C}}{\rho_{H}}}} \\
& \operatorname{Pr}\left(S=0 \mid \mu_{i 0, \ldots,} \mu_{i 6}\right)=\frac{\exp \left(\mu_{0}\right)}{\exp \left(\mu_{i 0}\right)+\left(\exp \left(\frac{\mu_{i 2}}{\rho_{H}}\right)+\left[\exp \left(\frac{\mu_{i 4}}{\rho_{C}}\right)+\exp \left(\frac{\mu_{i \theta}}{\rho_{c}}\right)\right]^{\frac{\rho_{C}}{\rho_{H}}}\right)^{\rho_{H}}} .
\end{aligned}
$$

The model is estimated by maximum likelihood restricting $\rho_{H}$ and $\rho_{C}$ between zero and one. This nested logit can also be interpreted as incorporating uncertainty in tastes for schooling. In this case it has the form of a forward-looking discrete choice dynamic programming model (see Taber $\Gamma 2000$ ).

There are a number of normalizations necessary for identification. We assume that $\beta_{T, S}$ is zero for dropouts which normalizes the location as in a standard in polychotomous choice models. In the high school equations we cannot separately identify the intercepts in $\beta_{T s}$ from the intercept in $\beta_{\ell s}$ so we set the latter to zero. In a feature that is more unique to our model we normalize the $\beta_{C}$ coefficient on distance from college to one in the equations for college. This normalization is needed because we cannot separately identify the scale of the indices from the intercept in the tastes for schooling index. ${ }^{19}$

It turned out that in practice the intercept in the cost equation was very difficult to identify empirically so we fixed it to two in the simulations we present. ${ }^{20}$ We experimented

\footnotetext{
${ }^{19}$ Normalizing this coefficient seems to work better computationally than the alternatives.

${ }^{20}$ The idea being that by living at home one can cut the cost of schooling in half.
} 
extensively with other values for this parameter and the results are not sensitive. In practice $\Gamma$ also had trouble identifying the coefficient on the local earnings variable in the two college states. A reduced form regression yields a value of approximately 0.3 for it $\Gamma$ so we fixed it to this value for the last two schooling equations. We again explored the sensitivity of our results to this assumption by trying alternative values and found our results to be very robust. We have also assumed that $\delta=0.97$ which yields $R=\frac{1}{\delta} \approx 1.031$.

The log-likelihood function for the model estimated without heterogeneity in access to credit is -2547.69 . The parameters are presented in Table 8. For the sake of brevity we do not provide a general discussion of the parameters $\Gamma$ but they seem reasonable to us.

The first case we examine is heterogeneity in interest rates across racial-ethnic groups. As mentioned above we include two dummy variables $\Gamma$ onefor African Americans and one for Hispanics. The results of this model are presented as the second group of results in Table 9. The point estimates go to the boundary in the unexpected direction and in the pseudo-likelihood ratio test ${ }^{21}$ we see no evidence that these are significant.

We next examine parental education. In this case we include variables for father's education and mother's education. These are presented as the third set of results in the table. Once again $\Gamma$ with a likelihood ratio test we cannot reject the null hypothesis of no heterogeneity in interest rates. In this case the point estimates go in the expected direction for mothers education $\Gamma$ but in the unexpected direction for fathers. The parameter for fathers seems to dominate in the simulations. Our next set of results interacts family income with access to credit. In this case we divide the data into three groups according to parental family income. We assume the top third to be not borrowing constrained and estimate the relative effect borrowing constraints influence the other two groups.

The estimated borrowing rates for the middle and bottom third are barely distinguishable from the rate for the top $\Gamma$ and again the results are statistically insignificart. Perhaps the case one might expect to find the strongest evidence for heterogeneity in credit access is family size. However $\Gamma$ the borrowing rate turns out to be insensitive to the number of children in the family (see "Number of Siblings" at the bottom of Table 9); the P-value of

\footnotetext{
${ }^{21}$ We call it a "pseudo likelihood ratio test" because the test depends on parameters the wage parameters $\Gamma$ which are estimated outside the model. Correcting the standard errors for the first stage estimates made very little difference $\Gamma$ so suspect that to be the case for the likelihood ratio test as well.
} 
an interaction between family size and borrowing rates is .99 .

\subsection{Evidence of Heterogeneity in Unobservable Borrowing Rates}

Failing to find evidence of heterogeneity in borrowing rates in the observables $\Gamma$ we extend the structural model in order to look for evidence in the unobservables. To begin $\Gamma$ assume there are two types of individuals $\Gamma$ those borroving at the market rate $R^{1}=1 / \delta$, and those borrowing at a higher rate $R^{2}>1 / \delta$. We estimate both the borrowing rate $\left(R^{2}\right)$ and the fraction of the population of each type $\left(P_{R^{i}}, i=1,2\right)$. We assume the distribution of borrowing rates is independent of the other error terms and the observables.

Heterogeneity in ability is assumed to enter the model through a single normally distributed factor $\theta_{i}$ which is known at the time schooling choices are made. The error term in the wage equation is defined as

$$
u_{s i t}=\phi_{w s} \theta_{i}+\omega_{s i t}
$$

where $\omega_{s i t}$ is orthogonal to $\theta_{i}$. Ability may also be correlated with unobserved tastes for schooling which are now defined as $\Gamma$

$$
\nu_{s i}=\phi_{T s} \theta_{i}+\tilde{\nu}_{s i}
$$

where $\widetilde{\nu}_{s i}$ has a GEV distribution yielding a nested logit model as in the previous section.

In this model $\Gamma$ economic identification guides the implementation of the model. This suggests that identification of the distribution of $R_{i}$ should come from the behavioral interaction between interest rates and costs and not from arbitrary functional form assumptions about the distribution of the error terms. These type of assumptions $\Gamma$ while common in structural models Thopelessly obscure the importance of estimated behavioral parameters. Avoiding this path leads us to two nonstandard strategies. First

sumption about the form of the selection bias $\Gamma$ are very flexible in modeling it. Ideally we would place no restrictions on the joint distribution of $\left(v_{2 i}, v_{4 i}, v_{6 i}, \omega_{0 i}, \omega_{2 i}, \omega_{0 i}, \omega_{2 i}\right)$. In practice $\Gamma$ the full distribution proved difficult too general to estimate and often led to a singular Hessian so standard errors could not be calculated. Nevertheless $\Gamma$ estimation of the distribution of $R_{i}$ was still possible $\mathrm{N}$ so we performed likelihood ratio tests to test for borrowing constraints. Full nonparametric estimation of the seven dimensional distribution 
was too general to be computationally feasible. Even though we have restricted the error terms to be normal with a one factor representation $\Gamma$ there are still seven parameters that determine the form of the selection bias: the corresponding seven factor loading terms on $\theta_{i}$. Even after restricting these parameters further we could not obtain standard errors. Keep in mind $\Gamma$ though $\Gamma$ we purposely chose to over-parameterize the form of the selection bias to force identification to come from the interaction between the bias and the college costs index.

Our second nonstandard strategy came from our desire to force identification of the distribution of $R_{i}$ to come from the form of selection bias as was suggested in the identification section above. We originally attempted to estimate the model by maximum likelihood. After extensive experimentation $\Gamma$ we concluded that this approach does not work well. Allowing general flexible forms to characterize the distribution of all of the error terms proved computational difficult $\Gamma$ and when restrictions were made on the functional form $\Gamma$ theestimated results appeared sensitive to the functional forms used. In particular $\Gamma$ we could not relax the distribution of $\omega_{s i}$ sufficiently so that we could really distinguish the distribution of $R_{i}$ from a more flexible functional from for the school choice equation. This is not at all in the spirit of our identification result above in which we showed that nonparametric identification of the distribution of $\theta_{i}$ comes from the form of the selection bias in the wage equation.

Instead $\Gamma$ we applied an iterative procedure to force identification of the distribution of $R_{i}$ and other parameters to come from the variation in data that we prefer to use. In particular $\Gamma$ we partition the parameters of our model to those we want to identify from the selection equation $\left(\Psi_{1}\right)$ and those that we want to identify in the wage equation $\left(\Psi_{2}\right)$. Denote all observables by $X_{i}$ and let $£_{i}\left(\Psi_{1}, \Psi_{2}, X_{i}\right)$ be the log likelihood from the schooling choice. We estimate the model using the following iterative procedure $\Gamma$

1. Fix $\Psi_{2}$ and solve for the value of $\Psi_{1}$ that maximizes the likelihood of the school choice model.

2. Fix $\Psi_{1}$ and solve for the value of $\Psi_{2}$ that minimizes the nonlinear least squares $\Gamma$

$$
\sum_{i=1}^{N} \sum_{t=1}^{T_{i}}\left(\log \left(w_{i t}\right)-E\left(\log \left(w_{i t}\right) \mid X_{i}, \Psi_{1}, \Psi_{2}\right)\right) \text {. }
$$


We iterate this procedure until convergence. ${ }^{22}$ This procedure is equivalent to a GMM model with moment conditions

$$
E\left[\begin{array}{l}
\frac{\partial \mathcal{E}_{i}\left(\Psi, X_{i}\right)}{\partial \Psi_{1}} \\
\frac{\partial E\left(\log \left(w_{i t}\right) \mid X_{i}, \Psi_{1}, \Psi_{2}\right)}{\partial \Psi_{2}}\left(\log \left(w_{i t}\right)-E\left(\log \left(w_{i t}\right) \mid X_{i}, \Psi_{1}, \Psi_{2}\right)\right)
\end{array}\right]=0 .
$$

The decision of which parameters to use in which equation was straight forward. The parameters of the wage equation we estimated from the regression model and the parameters of the tastes for schooling we estimated using the schooling choice model. Following the logic of the identification result we want the distribution of the borrowing rates to come from the wage equation $\Gamma$ so the distribution of $R_{i}$ was estimated from the regression model. Following the first strategy above $\Gamma$ the goal is to kep the form of the selection bias flexible so we estimate the factor loading terms on $\theta_{i}$ in the wage equation as well. That led us to the following partition $\Gamma$

$$
\begin{aligned}
& \left.\Psi_{1}=\left(\alpha_{1}, \rho_{H}, \rho_{c},\left(\beta_{T s}, \widetilde{\beta}_{\ell s}\right), s \in\{0,2,4,6\}\right)\right) \\
& \left.\Psi_{2}=\left(\beta_{W}, \beta_{\ell}, \beta_{E}, \beta_{E^{2}}, P_{R}, R^{2},\left(\gamma_{s}, \phi_{T s}, \phi_{w s}\right), s \in\{0,2,4,6\}\right)\right) .
\end{aligned}
$$

We experimented with a wide variety of specifications and starting values and found the model did not typically converge when we no restrictions were placed on the $\phi_{T s}$ parameters (factor loading on heterogeneity in taste for schooling). We restricted the model so that the taste for dropout and high school are the same $\left(\phi_{T 0}=\phi_{T 2}\right)$ and the taste for the two schooling types are the same $\left(\phi_{T 4}=\phi_{T 6}\right)$. Again this restriction did not appear to affect the basic result but did aid convergence substantially. ${ }^{23}$

The main result can be seen in the first two rows of Table 10. The model becomes degenerate finding that no individuals are borrowing constrained. We estimated the model using a large number of starting values and a number of different specifications and consistently found no evidence of heterogeneity in borrowing rates. The model estimates a borrowing rate of 1.071 for the borrowing constrained group (compared to 1.030 for the unconstrained group) but converges to a corner solution where the fraction of the population borrowing at the higher rate is zero. Because we are at a corner solution $\Gamma$ standard errors of the parameters could not be calculated.

\footnotetext{
${ }^{22}$ In practice we use a damping parameter to aid convergence.

${ }^{23} \mathrm{~A}$ linear specification for this parameter gave the same basic result.
} 
The wage parameters yield a strange pattern in that "some college" workers tend to have low wages although the schooling effects are monotonic otherwise. It is somewhat hard to interpret the results on the factor loading terms. The four factor loading terms are positive as one would expect $\Gamma$ although the point estimate of the college graduate factor loading term is substantially smaller than the others which is somewhat surprising. To get an idea of the precision to which these parameters are estimated we ran a simple OLS regression on the selection terms and the estimates of $E\left(\theta_{i} \mid S_{i}, X_{i} ; \Psi\right)$ ignoring the fact that we simultaneously estimated the parameters $\Psi$. By design this yields exactly the same point estimates as in Table 10 and yields standard errors on the factor loading terms $\left(\phi_{W s}\right)$ of approximately 0.12 . The rest of the parameters of the model are similar to our estimates without heterogeneity presented in Table 8 .

\section{Discussion and Conclusions}

This paper develops a model showing that direct costs of schooling affect borrowing constrained individuals in a fundamentally different way than opportunity costs of schooling. It then uses these two sources of variation to test for borrowing constraints in four different ways $\Gamma 1$ ) instrumental variables $\Gamma 2$ ) regressionmodels allowing for interactions between observables and presence of a college $\Gamma 3$ ) structuralestimation allowing borrowing rates to depend on observables $\Gamma$ 4) structural estimation allowing for unobservable heterogeneity in borrowing rates. We find no evidence of borrowing constraints using any of the methods.

One issue that inevitably arises with this type of finding is power. Have we found no evidence of borrowing constraints because there are not borrowing constraints or because we do not have enough precision to measure their significance? It is never possible to separate a claim that data or method lack power to identify a phenomenon from a claim that the phenomenon does not exist. In the end $\Gamma$ the answer a person chooses depends on her prior beliefs about the size of the effect. Our view is that power is much less of a concern in the regression framework and in the specification of the structural model that does not include unobserved borrowing rate heterogeneity. The college in county variable is very strong $\Gamma$ so if the irteraction with it were important we would expect to have power.

In contrast $\Gamma$ the instrumenal variable estimates of the returns to schooling are imprecise. 
It is less clear how much power we have in this case. In interpreting our results $\Gamma$ there are a number of things to keep in mind. First $\Gamma$ the evidence in support of discourt rate bias is also weak. There are a number of studies that find IV estimates are larger than OLS estimates $\Gamma$ but $\Gamma$ consistertly $\Gamma$ the IV standard errors in these studies are also large. Second $\Gamma$ a few recert studies instrument schooling with a variable like presence of a college. Our results show the sensitivity of these results to inclusion of the local income variable. Our findings suggest that proper inclusion of this variable in the analysis would weaken or eliminate the pattern of consistently finding IV estimates that are higher than OLS estimates. Third $\Gamma$ our result is not based on particularly poor standard errors. In fact $\Gamma$ point estimates consistently turn up with the wrong sign. Fourth potential problems with the instruments seem to bias things in the wrong direction. The regression results in Table 5 suggest that the estimate using presence of a college may be biased upwards $\Gamma$ while the argument about family contributions during economic recessions suggest that the IV estimates should be biased downwards. While these IV results in themselves may not be convincing evidence that borrowing constraints do not exist; at the very least $\Gamma$ they cast some doubt on the discount rate bias story for higher IV estimates. This is particularly true when these results are combined with the other cent evidence on borrowing constraints in schooling

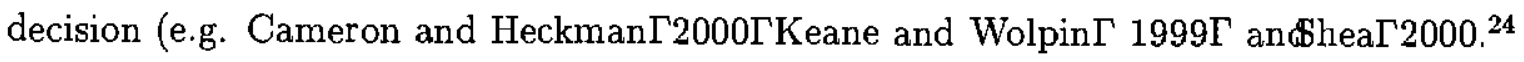

Given the problem in calculating standard errors in the structural selection model it is even harder to obtain a sense for the power in this model. Once again $\Gamma$ it is important to keep in mind that it is not just that we fail to reject the null $\Gamma$ but the point estimates show no evidence of heterogeneity in access to credit. We believe this basic approach is useful for examining this issue and hope it leads to additional studies on this topic.

In general our results are consistent with Cameron and Heckman (2000) ГKeane and Wolpin (1999) $\Gamma$ and Shea (2000) in that in all four methods te find no evidence of borrowing constraints. Once again $\Gamma$ it is importart to keep in mind that this does not necessarily mean that credit market constraints would not exist in the absence of the programs currently available. It implies instead that given the large range of subsidies to education that

\footnotetext{
${ }^{24}$ Ashenfelter and Harmon (1999) have an alternative argument for the IV findings in the literature. They argue that the pattern may be due to a troubling specification/publication bias. Since IV standard errors are often high $\Gamma$ if researkers prefer specifications in which the t-statistic is greater than two $\Gamma$ there will be a bias towards publishing studies with high IV estimates.
} 
currently exist $\Gamma$ there is no evidenceof inefficiencies in the schooling market resulting from borrowing constraints.

\section{References}

AltonjiГJ.ГЕlderГТ.Г and TaberГС.Г"Selection on Observed and Unobserved Variables: Assessing the Effectiveness of Catholic Schools $\Gamma$ "unpublished manuscript $\Gamma 2000$.

Angrist ГJ.Гand KruegerГА.Г "Empirical Strategies in Labor Economics $\Gamma$ "in Ashenfelter and Card eds. Handbook of Labor Economics, 2000.

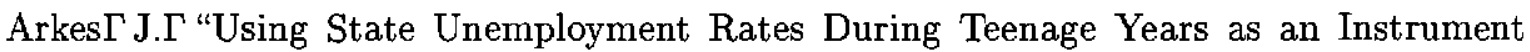
to Estimate the Returns to Schooling $\Gamma$ " unpublished manuscript $\Gamma$ Center for Naval Analyses $\Gamma 1998$.

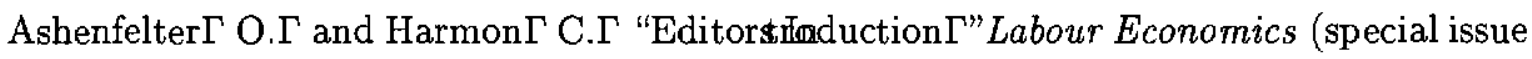
on education) $\Gamma$ forthcoming 1999.

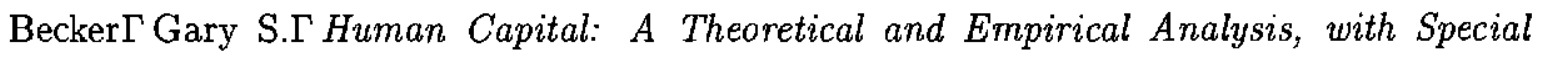
Reference to Education, (Chicago: University of Chicago Press) $\Gamma 1975$.

BlossfeldГН. and ShavitГY.Г1993. Persistent Inequality: Changing Educational Attainment in Thirteen Countries $\Gamma$ Boulder $\Gamma$ Co: Westview Press $\Gamma 1993$.

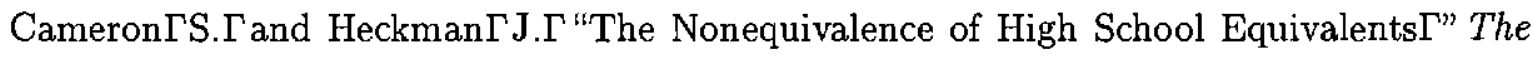
Journal of Labor Economics $\Gamma 11(1993) \Gamma 1-47$.

-_-_1998a. "Life Cycle Schooling and Educational Selectivity: Models and Choice $\Gamma$ " $\Gamma$ Journal of Political Economy April 1998.

1998b. "The Dynamics of Education Attainment for Blacks $\Gamma$ Whites $\Gamma$ and Hispanics $\Gamma$ " Columbia University manuscript $\Gamma$ 1998. Presented at NBER $\mathrm{A}$ April 1997.

Card $\Gamma$ Darid $\Gamma$ "Earnings $\Gamma$ Smooling $\Gamma$ and Ability Revisited $\Gamma$ "Research in Labor Economics 14, 1995аГ 23-48. 
Card $\Gamma$ David $\Gamma$ "Using Geographic Variation in College Proximity to Estimate the Return to Schooling $\Gamma$ "in Louis N. Christofides $\Gamma$ E. Kenneth Grant $\Gamma$ and Robert Swidinsky eds. Aspects of Labor Market Behavior: Essays in Honour of John Vanderkamp, (Toronto:University of Toronto Press) Г1995bГ201-222.

Card $\Gamma$ David $\Gamma$ "Estimating the Return to Schooling: Progress on Some Persistent Econometric Problems $\Gamma$ " unpublishedmanuscript $\Gamma 1999$.

Card $\Gamma$ Daid $\Gamma$ "The Causal Effect of Education on Earnings $\Gamma$ " in Ashenfelter and Card eds. Handbook of Labor Economics, 2000.

HauserГR.Г1993. "Trends in College Attendance Among Blacks $\Gamma$ Whites $\Gamma$ and Hispanics $\Gamma$." in Studies of Supply and Demand in Higher Education. C. Clotfelter and M. Rothschild $\Gamma$ eds. University of Chicago Press.

Heckman $\Gamma$ J. $\Gamma$ and SingerГ В.Г "A Method for Minimizing the Impact of Distributional Assumptions in Economic Models for Duration Data $\Gamma$ "Econometrica $\Gamma$ 52(1984) $\Gamma$ 271320 .

Heckman $\Gamma \mathrm{J}$. and Edward Vytlacil "Instrumental Variables for the Correlated Random Coefficient Model: Estimating the Average Rate of Return to Schooling when the Return is Correlated with Schooling $\Gamma$ " forthcoming $\Gamma$ Journal of Human Resources, 1998.

Imbens $\Gamma$ G. $\Gamma$ and Angrist $\Gamma J . \Gamma$ "Identification and Estimation of Local Average Treatment Effects $\Gamma "$ Econometrica $\Gamma$ 62(1994).

KaneГT. 1994. "College Entry by Blacks since 1970: The Role of College Costs $Г$ Family Background and the Returns to Education Г" Journal of Political Economy $\Gamma 102 \Gamma$ 878911.

Keane $\Gamma$ M. $\Gamma$ and Upin $\Gamma$ K. $\Gamma$ "The Effect of Arental Transfers and Borrowing Constraints on Educational Attainment $\Gamma$ " unpublishedmanuscript $\Gamma 1999$.

Kling $\Gamma$ Jeffrey $\Gamma$ "Interpreting Instrumental Variables Estimates of the Returns to Schooling $\Gamma^{\prime \prime}$ PrincetonIndustrial Sections Working paper no. 415Г 1999. 
Lang $\Gamma$ Kevin $\Gamma$ "Ability Bias $\Gamma$ Discount Rate Bias $\Gamma$ and the Return to Education $\Gamma$ " unpublished manuscript $\Gamma$ BostonUniversityГ 1994.

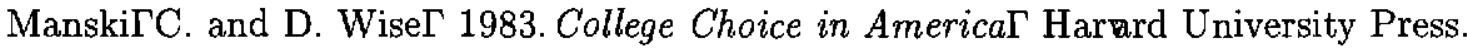

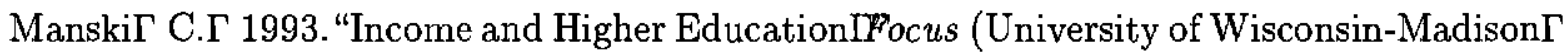
Institute for Research on Poverty) Vol $14 \Gamma$ No.3.

MareГR.D. 1980. "Social Background and School Continuation Decisions $\Gamma$ " Journal of The American Statistical Association $\Gamma 75$ (June) Г295-305.

MayerГS.Г1997. What Money Can't Buy, Harvard University Press.

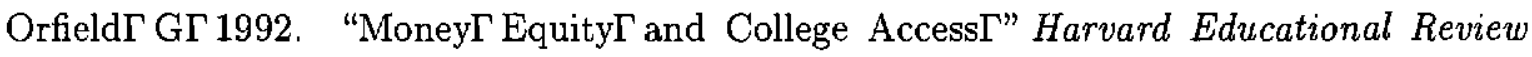
72(3)Г (Fall 19921):337-372.

RosenГS.Г 1977Г "Human Capital A Survey of Empirical Research $\Gamma$ " Research in Labor Economics Vol. 1, ed. R. EhrenbergГ3-39.

SheaГ J.Г 2000. "Does Parent's Money Matter?" forthcomingГ Journal of Public Economics.

TaberГС.ГГ"The Rising College Premium in the Eighties: Return to College or Return to Ability?" unpublished manuscript $\Gamma$ Northestern UniversityГ1999.

Willis $\Gamma$ R. $\Gamma$ "Wge Determinants: A Survey and Reinterpretation of Human Capital Earnings Functions $\Gamma$ " in O. Ashenfelter and F. Lyard eds. $\Gamma$ Handbook of Labor Economics $\Gamma$ Amsterdam $\Gamma$ NorthHolland $\Gamma 1986$.

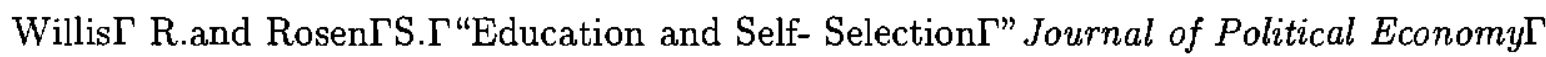
$87 \Gamma 1979$. 


\section{Appendix}

\section{A. Downward Bias of Schooling Returns when Instrumented with Foregone Earnings}

This section demonstrates how discount rate heterogeneity can bias downward the estimated return to schooling. Applying the methodology of Imbens and Angrist (1994) $\Gamma$ suppose schooling is binary with $S$ equal to either zero or one (loosely $\Gamma$ college or high shool). Local labor market conditions $\Gamma$ represented by $R \Gamma$ are binary with $R=1$ representing temporarily bad labor market conditions. Let $d(R)$ be an individual specific dummy variable equal to 1 if this individual would choose schooling level 1 in labor market condition $R$; that is $\Gamma$ defined(1) to indicate whether a person would attend college in a bad labor market $\Gamma$ and $d(0)$ to indicate attendance during a boom.

Let $W_{S}$ represent the wage a person would receive for schooling level $S \Gamma$ and let $W$ denote the unconditional wage. Assume $R$ is a legitimate instrument; that is $\Gamma$ it is uncorrelated with $\left(W_{1}, W_{0}, d(1), d(0)\right)$. The Wald estimate takes the form $\Gamma$

$$
\begin{aligned}
& \frac{E(W \mid R=1)-E(W \mid R=0)}{\operatorname{Pr}(S=\mathbf{1} \mid R=1)-\operatorname{Pr}(S=1 \mid R=0)} \\
= & \frac{E\left(W_{1} \mid R=1, d(1)=1\right) \operatorname{Pr}(d(\mathbf{1})=1)+E\left(W_{0} \mid R=1, d(1)=0\right) \operatorname{Pr}(d(\mathbf{1})=0)}{\operatorname{Pr}(d(\mathbf{1})=1)-\operatorname{Pr}(d(0)=1)} \\
& -\frac{E\left(W_{1} \mid R=0, d(0)=1\right) \operatorname{Pr}(d(0)=1)+E\left(W_{0} \mid R=0, d(0)=0\right) \operatorname{Pr}(d(0)=0)}{\operatorname{Pr}(d(1)=\mathbf{1})-\operatorname{Pr}(d(0)=1)} \\
= & \frac{E\left(W_{1} \mid d(\mathbf{1})=d(0)=1\right) \operatorname{Pr}(d(\mathbf{1})=d(0)=1)+E\left(W_{1} \mid d(1)>d(0)\right) \operatorname{Pr}(d(1)>d(0))}{\operatorname{Pr}(d(1)=\mathbf{1})-\operatorname{Pr}(d(0)=1)} \\
& +\frac{E\left(W_{0} \mid d(1)<d(0)\right) \operatorname{Pr}(d(1)<d(0))+E\left(W_{0} \mid d(\mathbf{1})=d(0)=0\right) \operatorname{Pr}(d(1)=d(0)=0)}{\operatorname{Pr}(d(1)=1)-\operatorname{Pr}(d(0)=1)} \\
& -\frac{E\left(W_{1} \mid d(1)=d(0)=\mathbf{1}\right) \operatorname{Pr}(d(1)=d(0)=1)+E\left(W_{1} \mid d(1)<d(0)\right) \operatorname{Pr}(d(1)<d(0))}{\operatorname{Pr}(d(1)=1)-\operatorname{Pr}(d(0)=1)} \\
& -\frac{E\left(W_{0} \mid d(1)>d(0)\right) \operatorname{Pr}(d(1)>d(0))+E\left(W_{0} \mid d(1)=d(0)=0\right) \operatorname{Pr}(d(1)=d(0)=0)}{\operatorname{Pr}(d(\mathbf{1})=1)-\operatorname{Pr}(d(0)=1)} \\
= & \frac{E\left(W_{1}-W_{0} \mid d(1)>d(0)\right) \operatorname{Pr}(d(1)>d(0))-E\left(W_{1}-W_{0} \mid d(1)<d(0)\right) \operatorname{Pr}(d(1)<d(0))}{\operatorname{Pr}(d(1)>d(0))-\operatorname{Pr}(d(1)<d(0))} .
\end{aligned}
$$

Our data show enrollment rises in bad labor markets. In this context $\Gamma$ Imbens and Angrist's (1994) monotonicity assumption implies people are induced to increase schooling only during a recession. That is $\Gamma$ there is no one in the population who would attend school 
during a boom who would not also attend during a recession: $\operatorname{Pr}(d(1)<d(0))=0$. Under this condition $\Gamma$ the Wald estimate reduces to $E\left(W_{1}-W_{0} \mid d(1)=1, d(0)=0\right)$. As argued in the text $\Gamma$ if changes in foregone earnings have little differential effect on borrowingconstrained and unconstrained persons $\Gamma$ then this estimate of the returns to schooling is not likely to be strongly influenced by "discount rate bias."

Now consider relaxing the monotonicity assumption. Suppose instead some borrowing constrained families cannot afford to send their children to college during a recession but would do so during a boom. In this case the monotonicity assumption is violated so $\operatorname{Pr}(d(1)<d(0))$ will be positive. To be consistent with the observation in the data that schooling rises during bad times $\Gamma$ it must be the case that $\operatorname{Pr}(d(1)=1, d(0)=0)>$ $\operatorname{Pr}(d(1)=0, d(0)=1)$. Under the discount rate bias hypothesis $\Gamma$ students from these borrowing constrained families have high marginal returns to college. This means that $E\left(W_{1}-W_{0} \mid d(1)<d(0)\right)$, would be large. Notice however that in this example this term enters the expression for the Wald estimate negatively. Thus in this case discount rate bias will bias this estimate downward.

\section{B. Identification of Structural Model}

Nonlinear models that impose linear index assumptions can often avoid the use of exclusion restrictions $\Gamma$ so to focus on the variation arising from the exclusion restriction we consider nonparametric identification of the model. Specifically we consider identification of $\Gamma$

$$
\begin{aligned}
S & =1\left(\log \left(e^{g_{1}(X)+\varepsilon_{1}}+g_{2}\left(Z_{1}\right)\right)+g_{3}(X)+g_{4}\left(Z_{2}\right)+\varepsilon_{2}>0\right) \\
\log \left(w_{1 t}\right) & =\gamma_{S}+g_{1}(X)+g_{t}\left(Z_{\ell t}\right)+e_{t} \beta_{E}+e_{t}^{2} \beta_{E^{2}}+u_{1} \\
\log \left(w_{0 t}\right) & =\gamma_{S}+g_{1}(X)+g_{t}\left(Z_{\ell t}\right)+e_{t} \beta_{E}+e_{t}^{2} \beta_{E^{2}}+u_{0}
\end{aligned}
$$

where $Z_{2}$ represents the exclusion restriction from local labor market conditions $\Gamma Z_{1}$ represents the exclusion restrictions that represent direct costs of schooling $\Gamma Z_{\ell t}$ represents local labor market variables at time $t$, and $X$ represents other regressors that influence wages and the tastes for schooling. ${ }^{25}$ The econometrician can observe $\left(X, Z_{2}, Z_{2}, Z_{\ell t}, e_{t}\right)$ and schooling

\footnotetext{
${ }^{25}$ The one type of variation we have not included in this specification is the local labor market variables that influence college choice. For this exercise we can fix them to a constant and only consider variation
} 
choice $S$. When $S=1 \Gamma w_{1 t}$ is observed and when $S=0, w_{0 t}$ is observed.

Before one can show identification $\Gamma$ there are some normalizations that must be imposed. First notice that we can always normalize $g_{3}(0)=g_{4}(0)=0$ by modifying the location of the error term $\varepsilon_{2}$. We need a scale normalization for $g_{2}$. As long as $g_{2}(0) \neq 0$,we can normalize $g_{2}(0)=1$. To see why we need a scale normalization can multiply $g_{2}$ by $e^{\tau}$, add $\tau$ to $\varepsilon_{1 i}$, and subtract $\tau$ rom $\varepsilon_{2 i}$ without changing the expression. Under these normalizations and standard assumptions about support conditions $\Gamma$ the model is identified.

Theorem 1 Normalize $g_{1}(0)=g_{3}(0)=g_{4}(0)=0$ and $g_{2}(0)=1$. Assume that (a) the support of $X$ does not depend on $\left(Z_{1}, Z_{2}\right)$, (b) $\left(g_{2}\left(Z_{1}\right), g_{4}\left(Z_{2}\right)\right)$ has support $\Re^{2}$, and (c) the error terms $\left(\varepsilon_{1}, \varepsilon_{2}, u_{1}, u_{2}\right)$ are independent of the observables $\left(X, Z_{2}, Z_{2}, Z_{\ell t}\right)$. Then $g_{1}, g_{2}, g_{3}$, and $g_{4}$ and the joint distribution of $\left(\varepsilon_{1 i}, \varepsilon_{2 i}, u_{1 i}\right)$ are identified.

Proof: First notice that we can use a standard identification at infinite argument (see e.g. Heckman $\Gamma 1990)$ to idetify $g_{1}$. That is send $g_{4}\left(Z_{2}\right) \rightarrow \infty$,and we can identify the form of the wage equation.

Now suppose the model is not identified so that there are two distinct models that explain the data $\Gamma$ thetrue model

$$
1\left(\log \left(e^{g_{1}(X)+\varepsilon_{1}}+g_{2}\left(Z_{1}\right)\right)+g_{3}(X)+g_{4}\left(Z_{2}\right)+\varepsilon_{2}>0\right)
$$

and an alternative model $\Gamma$

$$
1\left(\log \left(e^{g_{1}(X)+\varepsilon_{1}^{*}}+g_{2}^{*}\left(Z_{2}\right)\right)+g_{3}^{*}(X)+g_{4}^{*}\left(Z_{3}\right)+\varepsilon_{2}^{*}>0\right)
$$

We will show that these two models are equivalent.

Taking $g_{4}$ to the other side of the inequality sign and exponentiating both sides one can see that the distribution of $\Gamma$

$$
\omega_{1}=e^{g_{1}(X)+g_{3}(X)+\varepsilon_{1}+\varepsilon_{2}}+g_{2}\left(Z_{1}\right) e^{g_{3}(X)+\varepsilon_{2}}
$$

from the variables that influence local labor markets during college. We are assuming that $Z_{2}$ help predict local labor market levels $Z_{\ell t}$ during college. 
must be the same as the distribution of $\Gamma$

$$
\omega_{1}^{*}=f\left(e^{g_{1}(X)+g_{3}^{-}(X)+\varepsilon_{1}^{*}+\varepsilon_{2}^{*}}+g_{2}^{*}\left(Z_{1}\right) e^{g_{3}^{*}(X)+\varepsilon_{2}^{*}}\right)
$$

where $f$ is defined so that $e^{-g_{4}(X)}=f\left(e^{-g_{4}^{*}(X)}\right)$. Notice that

$$
\log \left(\frac{\partial E\left(\omega_{1} \mid X, Z_{1}, Z_{2}\right)}{\partial Z_{1}}\right)=\log \left(g_{2}^{\prime}\left(Z_{1}\right)\right)+g_{3}(X)+\log \left(E\left(e^{\varepsilon_{2}}\right)\right)
$$

which is separable in $Z_{1}$ and $X$. The only way that $\log \left(E\left(\omega_{1} \mid X, Z_{1}, Z_{2}\right)\right)$ can take this separable form is if $f$ is linear. The fact that $g_{4}(X)$ has full support and that $g_{4}(0)$ is normalized to zero implies that $g_{4}=g_{4}^{*}$.

Since

$$
\log \left(g_{2}^{\prime}\left(Z_{2}\right)\right)+g_{3}(X)+\log \left(E\left(e^{\varepsilon_{2}}\right)\right)=\log \left(g_{2}^{* \prime}\left(Z_{1}\right)\right)+g_{3}^{*}(X)+\log \left(E\left(e^{\varepsilon_{2}^{*}}\right)\right)
$$

$g_{3}$ and $g_{3}^{*}$ can only differ by a location parameter $\Gamma$ so since $g_{3}(0)$ is normalized to zero $\Gamma g_{3}$ is identified.

Since $g_{1}$ and $g_{3}$ are identified it must be that

$$
g_{2}^{*}\left(Z_{1}\right)=\frac{E\left(e^{\varepsilon_{2}^{*}}\right)}{E\left(e^{\varepsilon_{1}}\right)} g_{2}\left(Z_{*}\right)
$$

But since $g_{2}(0)=g_{2}(0)=1, g_{2}=g_{2}^{*}$. Thus $g_{1}, g_{2}, g_{3}$, and $g_{4}$ are all identified.

Now consider identification of the joint distribution of the error terms. Fixing $X=0 \Gamma$ $Z_{1}$ to a particular value $z_{1} \Gamma$ and varying $g_{4}\left(Z_{2}\right)$ we can identify the joint distribution of $\left(-\log \left(e^{\varepsilon_{1}}+g_{2}\left(z_{1}\right)\right)-\varepsilon_{2}, u_{1}\right)$ from

$$
\operatorname{Pr}\left(s_{i}=1, u_{1}<y\right)=\operatorname{Pr}\left(-\log \left(e^{\varepsilon_{1}}+g_{2}\left(z_{1}\right)\right)-\varepsilon_{2}<g_{4}\left(Z_{2}\right), u_{1}<y\right)
$$

Thus for any $\left(t_{1}, t_{2}\right) \in \Re^{2}$ we can identify $\Gamma$

$$
\begin{aligned}
E\left(\exp \left\{i\left(t_{1} e^{\log \left(e^{\varepsilon_{1}}+g_{2}\left(z_{1}\right)\right)+\varepsilon_{2}}+t_{2} u_{1}\right)\right\}\right) & =E\left(\exp \left\{i\left(t_{1} e^{\varepsilon_{1}+\varepsilon_{2}}+t_{1} g_{2}\left(z_{1}\right) e^{\varepsilon_{2}}+t_{2} u_{1}\right)\right\}\right) \\
& =\varphi\left(t_{1}, t_{1} g_{2}\left(z_{1}\right), t_{2}\right)
\end{aligned}
$$

where $\varphi$ characteristic function of $\left(e^{\varepsilon_{1 i}+\varepsilon_{2 i}}, e^{\varepsilon_{2 i}}, u_{1 i}\right)$. By varying $t_{1}, t_{2}$, and $g_{2}\left(z_{1}\right)$ we can identify the characteristic function and thus the joint distribution of $\left(e^{\varepsilon_{1}+\varepsilon_{2}}, e^{\varepsilon_{2}}, u_{1}\right)$. From this we can identify the distribution of $\left(\varepsilon_{1}, \varepsilon_{2}, u_{1}\right)$. 


\subsection{Identification of $\log (R)$ from $E\left(\theta_{1} \mid \theta_{1}-\log (R)\right)$}

We suspect that this result is not new although we have not found a source that proves it.

Proposition 2 Suppose that (a) $R$ is independent of $\theta_{1}$, (b) the distribution of $\left(\theta_{1}-\log (R)\right)$ is identified and (c) $E\left(\theta_{1} \mid \theta_{1}-\log (R)\right)$ is identified. Then the distribution of $R$ and $\theta_{1}$ are identified.

Proof: Let $\varphi_{\theta}$ and $\varphi_{R}$ be the characteristic functions of $\theta_{1}$ and $\log (R)$ respectively. Then we can identify $\Gamma$

$$
E\left(e^{i t\left(\theta_{1}-\log (R)\right)}\right)=\varphi_{\theta}(t) \varphi_{R}(-t)
$$

We can also identify

$$
\begin{aligned}
E\left(E\left(\theta_{1} \mid \theta_{1}-\log (R)\right) e^{i t\left(\theta_{1}-\log (R)\right)}\right) & =E\left(\theta_{1 i} e^{i t\left(\theta_{1}-\log (R)\right\}}\right) \\
& =E\left(\theta_{1 i} e^{i t\left(\theta_{1}\right)}\right) \varphi_{R_{i}}(-t)
\end{aligned}
$$

Thus we can identify the ratio $\Gamma$

$$
\begin{aligned}
\frac{i E\left(\theta_{1} e^{i t\left(\theta_{1}\right)}\right) \varphi_{R}(-t)}{\varphi_{\theta}(t) \varphi_{R}(-t)} & =\frac{E\left(i \theta_{1} e^{i t \theta_{1}}\right)}{\varphi_{\theta}(t)} \\
& =\frac{\partial \log \left(\varphi_{\theta}(t)\right)}{\partial t}
\end{aligned}
$$

But this means that $\varphi_{\theta}$ and thus the distribution of $\theta_{1}$ is identified. Given this and $\varphi_{\theta}(t) \varphi_{R}(-t)$, then $\varphi_{R}$ and thus the distribution of $\log (R)$ are identified. 
Table 1

Summary Statistics

Primary Variables

\begin{tabular}{lccc}
\hline \hline Variable & Mean & Standard Deviation & Sample Size \\
\hline Years of Schooling & 12.802 & 2.487 & 2404 \\
College in County & 0.867 & 0.340 & 2404 \\
Local Income at 17 & 12.845 & 2.385 & 2404 \\
Black & 0.314 & 0.464 & 2404 \\
Hispanic & 0.186 & 0.389 & 2404 \\
AFQT Score & 0.579 & 22.140 & 2404 \\
Math Score & 0.181 & 8.439 & 2404 \\
Word Knowledge & 0.172 & 8.439 & 2404 \\
General Science & 0.098 & 5.388 & 2404 \\
Automotive Knowledge & 0.039 & 5.443 & 2404 \\
Highest Grade Father & 10.503 & 4.103 & 2404 \\
Highest Grade Mother & 10.780 & 3.211 & 2404 \\
Number of Siblings & 3.734 & 2.626 & 2404 \\
Family Income & 3.356 & 2.065 & 2404 \\
Experience & 7.536 & 3.169 & 13762 \\
Local Income & 13.919 & 3.479 & 13762 \\
\hline
\end{tabular}


Table 2

First Stage Regression of

Schooling on Explanatory Variables

(Standard Errors in Parentheses) ${ }^{\natural}$

\begin{tabular}{|c|c|c|c|c|}
\hline Variable & $(1)$ & $(2)$ & (3) & $(4)$ \\
\hline College in County & $\begin{array}{c}0.417 \\
(0.152)\end{array}$ & & & $\begin{array}{c}0.435 \\
(0.148)\end{array}$ \\
\hline Local Income at 17 & & $\begin{array}{l}-0.023 \\
(0.021)\end{array}$ & $\begin{array}{l}-0.182 \\
(0.074)\end{array}$ & $\begin{array}{l}-0.183 \\
(0.074)\end{array}$ \\
\hline $\begin{array}{l}\text { Mean Local Income over } \\
\text { Working Life }\end{array}$ & & & $\begin{array}{c}0.130 \\
(0.058)\end{array}$ & $\begin{array}{c}0.123 \\
(0.058)\end{array}$ \\
\hline Black & $\begin{array}{c}0.688 \\
(0.124)\end{array}$ & $\begin{array}{c}0.723 \\
(0.124)\end{array}$ & $\begin{array}{c}0.691 \\
(0.123)\end{array}$ & $\begin{array}{c}0.677 \\
(0.124)\end{array}$ \\
\hline Hispanic & $\begin{array}{c}0.334 \\
(0.138)\end{array}$ & $\begin{array}{c}0.359 \\
(0.143)\end{array}$ & $\begin{array}{l}0.3 \\
(0.1\end{array}$ & $\begin{array}{c}0.345 \\
(0.141)\end{array}$ \\
\hline Math Score & $\begin{array}{c}0.167 \\
(0.010)\end{array}$ & $\begin{array}{c}0.168 \\
(0.010)\end{array}$ & $\begin{array}{c}0.167 \\
(0.010\end{array}$ & $\begin{array}{c}0.166 \\
(0.010)\end{array}$ \\
\hline Word Knowledge & $\begin{array}{c}0.050 \\
(0.010)\end{array}$ & $\begin{array}{c}0.050 \\
(0.009)\end{array}$ & $\begin{array}{c}0.050 \\
(0.010)\end{array}$ & $\begin{array}{c}0.050 \\
(0.010)\end{array}$ \\
\hline General Science & $\begin{array}{c}0.065 \\
(0.015)\end{array}$ & $\begin{array}{l}0.066 \\
(0.015)\end{array}$ & $\begin{array}{l}0.066 \\
(0.015)\end{array}$ & $\begin{array}{c}0.065 \\
(0.015)\end{array}$ \\
\hline Automotive Knowledge & $\begin{array}{c}-0.065 \\
(0.011)\end{array}$ & $\begin{array}{c}-0.069 \\
(0.010)\end{array}$ & $\begin{array}{c}-0.065 \\
(0.011)\end{array}$ & $\begin{array}{c}-0.066 \\
(0.011)\end{array}$ \\
\hline Highest Grade Father & $\begin{array}{c}0.051 \\
(0.016)\end{array}$ & $\begin{array}{c}0.053 \\
(0.016)\end{array}$ & $\begin{array}{c}0.052 \\
(0.016)\end{array}$ & $\begin{array}{c}0.050 \\
(0.016)\end{array}$ \\
\hline Highest Grade Mother & $\begin{array}{c}0.038 \\
(0.022)\end{array}$ & $\begin{array}{c}0.039 \\
(0.022)\end{array}$ & $\begin{array}{l}0.039 \\
(0.022)\end{array}$ & $\begin{array}{c}0.039 \\
(0.022)\end{array}$ \\
\hline Number of Siblings & $\begin{array}{l}-0.044 \\
(0.016)\end{array}$ & $\begin{array}{l}-0.047 \\
(0.016)\end{array}$ & $\begin{array}{l}-0.047 \\
(0.016)\end{array}$ & $\begin{array}{l}-0.046 \\
(0.016)\end{array}$ \\
\hline Family Income & $\begin{array}{c}0.090 \\
(0.022)\end{array}$ & $\begin{array}{c}0.094 \\
(0.022)\end{array}$ & $\begin{array}{c}0.095 \\
(0.022)\end{array}$ & $\begin{array}{c}0.095 \\
(0.022)\end{array}$ \\
\hline Constant & $\begin{array}{c}11.320 \\
(0.273)\end{array}$ & $\begin{array}{c}11.710 \\
(0.335)\end{array}$ & $\begin{array}{c}11.993 \\
(0.371)\end{array}$ & $\begin{array}{l}11.886 \\
(0.321)\end{array}$ \\
\hline Geographic Controls & Yes & Yes & Yes & Yes \\
\hline Cohor & Yes & Ye: & $\mathrm{Y}$ & Yes \\
\hline Sample Size & 2404 & 2404 & 2404 & 2404 \\
\hline
\end{tabular}

$\S$ The standard errors are constructed to allow for arbitrary correlation between individuals from the same county at age 17 
Table 3

Results for Log Wage Regressions

OLS and IV Estimates

Using Foregone Earnings as Instrument

(Standard Errors in Parentheses) $^{\S}$

\begin{tabular}{|c|c|c|c|c|c|c|}
\hline & OLS & IV1 & IV2 & OLS & IV1 & IV2 \\
\hline Schooling & 0.058 & 0.083 & 0.110 & 0.074 & 0.107 & 0.134 \\
\hline & & & $(0.086)$ & $(0.004)$ & $(0.034)$ & $(0.061)$ \\
\hline Local Income & $\begin{array}{c}0.027 \\
(0.003)\end{array}$ & $\begin{array}{c}0.035 \\
(0.006)\end{array}$ & $\begin{array}{c}0.036 \\
(0.005)\end{array}$ & $\begin{array}{c}0.025 \\
(0.003)\end{array}$ & $\begin{array}{c}0.031 \\
(0.005)\end{array}$ & $\begin{array}{c}0.034 \\
(0.005)\end{array}$ \\
\hline Experience & $\begin{array}{c}0.054 \\
(0.006)\end{array}$ & $\begin{array}{c}0.065 \\
(0.018)\end{array}$ & $\begin{array}{c}0.091 \\
(0.023)\end{array}$ & $\begin{array}{c}0.055 \\
(0.006)\end{array}$ & $\begin{array}{c}0.074 \\
(0.019)\end{array}$ & $\begin{array}{c}0.083 \\
(0.022)\end{array}$ \\
\hline Experience Squared & $\begin{array}{c}-0.002 \\
(0.000)\end{array}$ & $\begin{array}{c}-0.002 \\
(0.000)\end{array}$ & $\begin{array}{c}-0.004 \\
(0.001)\end{array}$ & $\begin{array}{c}-0.002 \\
(0.000)\end{array}$ & $\begin{array}{l}-0.002 \\
(0.001)\end{array}$ & $\begin{array}{c}-0.004 \\
(0.001)\end{array}$ \\
\hline Black & $\begin{array}{c}-0.063 \\
(0.024)\end{array}$ & $\begin{array}{c}-0.085 \\
(0.031)\end{array}$ & $\begin{array}{c}-0.115 \\
(0.061)\end{array}$ & $\begin{array}{l}-0.148 \\
(0.022)\end{array}$ & $\begin{array}{c}-0.162 \\
(0.022)\end{array}$ & $\begin{array}{c}-0.178 \\
(0.028)\end{array}$ \\
\hline Hispanic & $\begin{array}{c}-0.020 \\
(0.030)\end{array}$ & $\begin{array}{c}-0.033 \\
(0.029)\end{array}$ & $\begin{array}{c}-0.041 \\
(0.034)\end{array}$ & $\begin{array}{c}-0.061 \\
(0.030)\end{array}$ & $\begin{array}{l}-0.074 \\
(0.029)\end{array}$ & $\begin{array}{c}-0.085 \\
(0.032)\end{array}$ \\
\hline Highest Grade Father & $\begin{array}{c}-0.003 \\
(0.004)\end{array}$ & $\begin{array}{c}-0.005 \\
(0.005)\end{array}$ & $\begin{array}{c}-0.008 \\
(0.010)\end{array}$ & $\begin{array}{l}-0.001 \\
(0.004)\end{array}$ & $\begin{array}{l}-0.005 \\
(0.006)\end{array}$ & $\begin{array}{c}-0.013 \\
(0.014)\end{array}$ \\
\hline Highest Grade Mother & $\begin{array}{c}-0.005 \\
(0.005)\end{array}$ & $\begin{array}{c}-0.008 \\
(0.006)\end{array}$ & $\begin{array}{c}-0.012 \\
(0.011)\end{array}$ & $\begin{array}{l}-0.001 \\
(0.005)\end{array}$ & $\begin{array}{l}-0.007 \\
(0.007)\end{array}$ & $\begin{array}{c}-0.015 \\
(0.014)\end{array}$ \\
\hline Number of Siblings & $\begin{array}{c}0.002 \\
(0.003)\end{array}$ & $\begin{array}{c}0.003 \\
(0.004)\end{array}$ & $\begin{array}{c}0.005 \\
(0.005)\end{array}$ & $\begin{array}{c}-0.001 \\
(0.005)\end{array}$ & $\begin{array}{c}0.001 \\
(0.004)\end{array}$ & $\begin{array}{c}0.005 \\
(0.007)\end{array}$ \\
\hline Math Score & $\begin{array}{c}0.010 \\
(0.002)\end{array}$ & $\begin{array}{c}0.007 \\
(0.005)\end{array}$ & $\begin{array}{c}0.002 \\
(0.014)\end{array}$ & & & \\
\hline Word Knowledge & $\begin{array}{c}0.002 \\
(0.002)\end{array}$ & $\begin{array}{c}0.001 \\
(0.002)\end{array}$ & $\begin{array}{c}-0.000 \\
(0.004)\end{array}$ & & & \\
\hline General Science & $\begin{array}{c}-0.004 \\
(0.003)\end{array}$ & $\begin{array}{c}-0.005 \\
(0.003)\end{array}$ & $\begin{array}{c}-0.006 \\
(0.006)\end{array}$ & & & \\
\hline Automotive Knowledge & $\begin{array}{c}0.012 \\
(0.002)\end{array}$ & $\begin{array}{c}0.014 \\
(0.003)\end{array}$ & $\begin{array}{c}0.016 \\
(0.007)\end{array}$ & & & \\
\hline Family Income & $\begin{array}{c}0.036 \\
(0.005)\end{array}$ & $\begin{array}{c}0.034 \\
(0.005)\end{array}$ & $\begin{array}{c}0.031 \\
(0.007)\end{array}$ & $\begin{array}{c}0.042 \\
(0.005)\end{array}$ & $\begin{array}{c}0.039 \\
(0.006)\end{array}$ & $\begin{array}{c}0.034 \\
(0.005)\end{array}$ \\
\hline Geographic & Yes & Yes & Yes & Yes & Yes & Yes \\
\hline Cohort Controls & Yes & Yes & Yes & Yes & Yes & Yes \\
\hline Instruments: & & & & & & \\
\hline Local Income at 17 & & Yes & Yes & & Yes & Yes \\
\hline Current Local IncГCounty 17 & & Yes & Yes & & Yes & Yes \\
\hline Age and $\mathrm{AGE}^{2}$ & & No & Yes & & No & Yes \\
\hline Number of Individ & 2225 & $22 \overline{25}$ & 2225 & 2225 & 2225 & 2225 \\
\hline Number of Wage Years & 13762 & 13762 & 13762 & 13762 & 13762 & 13762 \\
\hline
\end{tabular}

$\mathrm{f}$ The standard errors are constructed to allow for arbitrary correlation between individuals from the same county at age 17 
Table 4a

Results for Log Wage Regressions

OLS and IV Estimates

Using Presence of Local College as Instrument

(Standard Errors in Parentheses) ${ }^{\S}$

\begin{tabular}{|c|c|c|c|c|c|c|}
\hline & OLS & IV1 & IV2 & OLS & $\overline{\text { IV1 }}$ & IV2 \\
\hline \multirow[t]{2}{*}{ Schooling } & 0.062 & 0.228 & 0.193 & 0.058 & 0.057 & 0.061 \\
\hline & $(0.004)$ & $(0.109)$ & $(0.084)$ & $(0.004)$ & $(0.115)$ & $(0.076)$ \\
\hline \multirow[t]{2}{*}{ Local Income } & & & & 0.027 & 0.035 & 0.035 \\
\hline & & & & $(0.002)$ & $(0.006)$ & $(0.005)$ \\
\hline \multirow[t]{2}{*}{ Experience } & 0.054 & 0.124 & 0.075 & 0.054 & 0.054 & 0.102 \\
\hline & $(0.006)$ & $(0.047)$ & $(0.020)$ & $(0.006)$ & $(0.049)$ & $(0.019)$ \\
\hline \multirow[t]{2}{*}{ Experience Squared } & -0.002 & -0.003 & -0.004 & -0.002 & -0.002 & -0.005 \\
\hline & $(0.000)$ & $(0.001)$ & $(0.001)$ & $(0.000)$ & $(0.001)$ & $(0.001)$ \\
\hline \multirow[t]{2}{*}{ Black } & -0.029 & -0.111 & -0.119 & -0.063 & -0.073 & -0.082 \\
\hline & $(0.026)$ & $(0.066)$ & $(0.067)$ & $(0.023)$ & $(0.063)$ & $(0.059)$ \\
\hline \multirow[t]{2}{*}{ Hispanic } & 0.009 & -0.023 & -0.020 & -0.020 & -0.028 & -0.029 \\
\hline & $(0.035)$ & $(0.045)$ & $(0.044)$ & $(0.026)$ & $(0.037)$ & $(0.036)$ \\
\hline \multirow[t]{2}{*}{ Highest Grade Father } & -0.003 & -0.014 & -0.015 & -0.003 & -0.003 & -0.003 \\
\hline & $(0.004)$ & $(0.009)$ & $(0.010)$ & $(0.004)$ & $(0.008)$ & $(0.008)$ \\
\hline \multirow[t]{2}{*}{ Highest Grade Mother } & -0.002 & -0.016 & -0.017 & -0.005 & -0.006 & -0.006 \\
\hline & $(0.005)$ & $(0.010)$ & $(0.011)$ & $(0.005)$ & $(0.010)$ & $(0.010)$ \\
\hline \multirow[t]{2}{*}{ Number of Siblings } & -0.001 & 0.003 & 0.005 & 0.002 & 0.003 & 0.003 \\
\hline & $(0.004)$ & $(0.005)$ & $(0.005)$ & $(0.003)$ & $(0.005)$ & $(0.005)$ \\
\hline \multirow[t]{2}{*}{ Math Score } & 0.010 & -0.008 & -0.010 & 0.010 & 0.010 & 0.010 \\
\hline & $(0.002)$ & $(0.013)$ & $(0.014)$ & $(0.002)$ & $(0.013)$ & $(0.013)$ \\
\hline \multirow[t]{2}{*}{ Word Knowledge } & 0.003 & -0.001 & -0.002 & 0.002 & 0.002 & 0.002 \\
\hline & $(0.002)$ & $(0.004)$ & $(0.004)$ & $(0.002)$ & $(0.003)$ & $(0.003)$ \\
\hline \multirow[t]{2}{*}{ General Science } & -0.005 & -0.012 & -0.013 & -0.004 & -0.003 & -0.003 \\
\hline & $(0.003)$ & $(0.006)$ & $(0.006)$ & $(0.003)$ & $(0.006)$ & $(0.005)$ \\
\hline \multirow[t]{2}{*}{ Automotive Knowledge } & 0.009 & 0.017 & 0.018 & 0.012 & 0.012 & 0.012 \\
\hline & $(0.002)$ & $(0.005)$ & $(0.006)$ & $(0.002)$ & $(0.005)$ & $(0.005)$ \\
\hline \multirow[t]{2}{*}{ Family Income } & 0.039 & 0.033 & 0.032 & 0.036 & 0.035 & 0.034 \\
\hline & $(0.005)$ & $(0.007)$ & $(0.007)$ & $(0.005)$ & $(0.006)$ & $(0.007)$ \\
\hline Geographic Controls & Yes & Yes & Yes & Yes & Yes & Yes \\
\hline Cohort Controls & Yes & Yes & Yes & Yes & Yes & Yes \\
\hline \multicolumn{7}{|l|}{ Instruments: } \\
\hline College in County & & Yes & Yes & & Yes & Yes \\
\hline Current Local Inc $\Gamma$ County 17 & & No & No & & Yes & Yes \\
\hline Age and $\mathrm{AGE}^{2}$ & & No & Yes & & No & Yes \\
\hline Number of Individuals & 2225 & 2225 & 2225 & 2225 & 2225 & 2225 \\
\hline Number of Wage Years & 13762 & 13762 & 13762 & 13762 & 13762 & 13762 \\
\hline
\end{tabular}

$\S$ The standard errors are constructed to allow for arbitrary correlation

between individuals from the same county at age 17 
Table 4b

Results for Log Wage Regressions

OLS and TV Estimates

Using Presence of Local College as Instrument

(Standard Errors in Parentheses)

\begin{tabular}{|c|c|c|c|c|c|c|}
\hline & OLS & IV1 & IV2 & OLS & IV1 & IV2 \\
\hline \multirow[t]{2}{*}{ Schooling } & 0.054 & 0.027 & 0.042 & 0.074 & 0.052 & $0.0 \overline{65}$ \\
\hline & $(0.004)$ & $(0.095)$ & $(0.060)$ & $(0.004)$ & $(0.078)$ & $(0.046)$ \\
\hline \multirow[t]{2}{*}{ Local Income } & 0.026 & 0.035 & 0.034 & 0.025 & 0.031 & 0.031 \\
\hline & $(0.002)$ & $(0.006)$ & $(0.006)$ & $(0.002)$ & $(0.006)$ & $(0.006)$ \\
\hline \multirow[t]{2}{*}{ Experience } & 0.054 & 0.042 & 0.106 & 0.055 & 0.043 & 0.104 \\
\hline & $(0.006)$ & $(0.046)$ & $(0.017)$ & $(0.006)$ & $(0.044)$ & $(0.016)$ \\
\hline \multirow[t]{2}{*}{ Experience Squared } & -0.002 & -0.002 & -0.005 & -0.002 & -0.002 & -0.005 \\
\hline & $(0.000)$ & $(0.001)$ & $(0.001)$ & $(0.000)$ & $(0.001)$ & $(0.001)$ \\
\hline \multirow[t]{2}{*}{ Black } & -0.081 & -0.077 & -0.087 & -0.147 & -0.154 & -0.160 \\
\hline & $(0.021)$ & $(0.066)$ & $(0.062)$ & $(0.021)$ & $(0.026)$ & $(0.026)$ \\
\hline \multirow[t]{2}{*}{ Hispanic } & -0.040 & -0.043 & -0.043 & -0.061 & -0.065 & -0.064 \\
\hline & $(0.026)$ & $(0.040)$ & $(0.040)$ & $(0.026)$ & $(0.032)$ & $(0.033)$ \\
\hline \multirow[t]{2}{*}{ Highest Grade Father } & -0.004 & -0.002 & -0.001 & -0.001 & 0.001 & 0.002 \\
\hline & $(0.004)$ & $(0.009)$ & $(0.009)$ & $(0.004)$ & $(0.010)$ & $(0.010)$ \\
\hline \multirow[t]{2}{*}{ Highest Grade Mother } & -0.006 & -0.005 & -0.005 & -0.001 & 0.001 & 0.000 \\
\hline & $(0.005)$ & $(0.008)$ & $(0.008)$ & $(0.005)$ & $(0.011)$ & $(0.010)$ \\
\hline \multirow[t]{2}{*}{ Number of Siblings } & 0.002 & 0.003 & 0.003 & -0.001 & -0.001 & -0.001 \\
\hline & $(0.003)$ & $(0.004)$ & $(0.004)$ & $(0.003)$ & $(0.006)$ & $(0.006)$ \\
\hline \multirow[t]{2}{*}{ AFQT Score } & 0.005 & 0.006 & 0.006 & & & \\
\hline & $(0.000)$ & $(0.004)$ & $(0.003)$ & & & \\
\hline \multirow[t]{2}{*}{ Family Income } & 0.036 & 0.036 & 0.036 & 0.042 & 0.044 & 0.043 \\
\hline & $(0.005)$ & $(0.006)$ & $(0.006)$ & $(0.005)$ & $(0.009)$ & $(0.009)$ \\
\hline $\begin{array}{l}\text { Geographic Controls } \\
\text { Cohort Controls }\end{array}$ & Yes & Yes & Yes & Yes & Yes & Yes \\
\hline \multicolumn{7}{|l|}{ Instruments: } \\
\hline College In County & & Yes & Yes & & Yes & Yes \\
\hline Current Local IncГCounty 17 & & Yes & Yes & & Yes & Yes \\
\hline Age and $\mathrm{AGE}^{2}$ & & No & Yes & & No & Yes \\
\hline Number of Individuals & 2225 & 2225 & 2225 & 2225 & 2225 & $22 \overline{25}$ \\
\hline Number of Wage Years & 13762 & 13762 & 13762 & 13762 & 13762 & 13762 \\
\hline
\end{tabular}

$\S$ The standard errors are constructed to allow for arbitrary correlation

between individuals from the same county at age 17 
Table 5

Regression of Instrumental Variables on other Determinants of Schooling and Wages (Standard Errors in Parentheses)

\begin{tabular}{|c|c|c|}
\hline \multirow[b]{2}{*}{ Covariate } & \multicolumn{2}{|c|}{ Dependent Variable } \\
\hline & $\begin{array}{l}\text { College in } \\
\text { County }\end{array}$ & $\begin{array}{l}\text { Local Income } \\
\text { at Seventeen }\end{array}$ \\
\hline College in County & & $\begin{array}{c}0.038 \\
(0.091)\end{array}$ \\
\hline Local Wage at 17 & $\begin{array}{c}0.006 \\
(0.014)\end{array}$ & \\
\hline Mean Local Income over & 0.013 & 0.748 \\
\hline Working Life & $(0.011)$ & $(0.017)$ \\
\hline Black & $\begin{array}{c}0.032 \\
(0.035)\end{array}$ & $\begin{array}{l}-0.094 \\
(0.070)\end{array}$ \\
\hline Hispanic & $\begin{array}{c}0.005 \\
(0.037)\end{array}$ & $\begin{array}{l}-0.007 \\
(0.078)\end{array}$ \\
\hline Math Score/10 & $\begin{array}{c}0.030 \\
(0.016)\end{array}$ & $\begin{array}{l}-0.052 \\
(0.033)\end{array}$ \\
\hline Word Knowledge/10 & $\begin{array}{c}0.014 \\
(0.014)\end{array}$ & $\begin{array}{c}0.022 \\
(0.054)\end{array}$ \\
\hline General Science/10 & $\begin{array}{c}0.023 \\
(0.024)\end{array}$ & $\begin{array}{c}0.022 \\
(0.054)\end{array}$ \\
\hline Automotive Knowledge & $\begin{array}{l}-0.053 \\
(0.017)\end{array}$ & $\begin{array}{l}-0.006 \\
(0.043)\end{array}$ \\
\hline Highest Grade Father & $\begin{array}{c}0.006 \\
(0.002)\end{array}$ & $\begin{array}{l}-0.004 \\
(0.007)\end{array}$ \\
\hline Highest Grade Mother & $\begin{array}{l}-0.001 \\
(0.003)\end{array}$ & $\begin{array}{l}-0.001 \\
(0.007)\end{array}$ \\
\hline Number of Siblings & $\begin{array}{l}-0.002 \\
(0.003)\end{array}$ & $\begin{array}{c}0.007 \\
(0.007)\end{array}$ \\
\hline Family Income & $\begin{array}{l}-0.001 \\
(0.003)\end{array}$ & $\begin{array}{c}0.035 \\
(0.012)\end{array}$ \\
\hline Sample Size & 2413 & 2413 \\
\hline
\end{tabular}


Table 6

Determinants of College Attendance and High School Dropout

Average Derivatives from Probit Model

(Standard Errors in Parentheses)

\begin{tabular}{|c|c|c|}
\hline \multirow[b]{3}{*}{ Covariate } & \multicolumn{2}{|c|}{ Dependent Variable } \\
\hline & College & High School \\
\hline & Attendance & Dropout \\
\hline \multirow[t]{2}{*}{ College in County } & 0.166 & -0.035 \\
\hline & $(0.036)$ & $(0.030)$ \\
\hline \multirow[t]{2}{*}{ Local Income at 17} & -0.043 & 0.028 \\
\hline & $(0.022)$ & $(0.016)$ \\
\hline Mean Local Income over & 0.035 & -0.009 \\
\hline Working Life & $(0.017)$ & $(0.013)$ \\
\hline \multirow[t]{2}{*}{ Black } & 0.170 & -0.109 \\
\hline & $(0.037)$ & $(0.023)$ \\
\hline \multirow[t]{2}{*}{ Hispanic } & 0.144 & -0.034 \\
\hline & $(0.041)$ & $(0.024)$ \\
\hline \multirow[t]{2}{*}{ Math Score } & 0.032 & -0.020 \\
\hline & $(0.003)$ & $(0.002)$ \\
\hline \multirow[t]{2}{*}{ Word Knowledge } & 0.017 & -0.007 \\
\hline & $(0.003)$ & $(0.002)$ \\
\hline \multirow[t]{2}{*}{ General Science } & 0.010 & -0.006 \\
\hline & $(0.004)$ & $(0.003)$ \\
\hline \multirow[t]{2}{*}{ Automotive Knowledge } & -0.013 & 0.002 \\
\hline & $(0.003)$ & $(0.002)$ \\
\hline \multirow[t]{2}{*}{ Highest Grade Father } & 0.013 & -0.003 \\
\hline & $(0.004)$ & $(0.003)$ \\
\hline \multirow[t]{2}{*}{ Highest Grade Mother } & 0.010 & -0.004 \\
\hline & $(0.007)$ & $(0.004)$ \\
\hline \multirow[t]{2}{*}{ Number of Siblings } & -0.016 & 0.004 \\
\hline & $(0.005)$ & $(0.003)$ \\
\hline \multirow[t]{2}{*}{ Family Income } & 0.011 & -0.023 \\
\hline & $(0.007)$ & $(0.005)$ \\
\hline Geographic Controls & Yes & Yes \\
\hline Cohort Controls & Yes & Yes \\
\hline Sample Size & 2404 & 2404 \\
\hline
\end{tabular}




\section{Table 7}

Schooling Regressions

on College in County interacted with

Alternative Covariates

(Standard Errors in Parentheses)

\begin{tabular}{|c|c|c|c|c|}
\hline Covariate & (1) & (2) & $(3)$ & (4) \\
\hline \multirow[t]{2}{*}{ College in County } & 0.596 & 3.149 & 0.103 & 0.592 \\
\hline & $(0.166)$ & $(0.072)$ & $(0.236)$ & $(0.229)$ \\
\hline \multirow[t]{2}{*}{ Local Income at 17} & -0.102 & -0.074 & -0.107 & -0.104 \\
\hline & $(0.059)$ & $(0.038)$ & $(0.059)$ & $(0.058)$ \\
\hline Mean Local Income over & 0.067 & 0.038 & 0.068 & 0.065 \\
\hline Working Life & $(0.046)$ & $(0.031)$ & $(0.046)$ & $(0.046)$ \\
\hline \multirow[t]{2}{*}{ Black } & 0.968 & 0.333 & 0.690 & 0.689 \\
\hline & $(0.211)$ & $(0.086)$ & $(0.125)$ & $(0.125)$ \\
\hline \multirow[t]{2}{*}{ Hispanic } & 0.914 & 0.018 & 0.347 & 0.344 \\
\hline & $(0.379)$ & $(0.105)$ & $(0.142)$ & $(0.142)$ \\
\hline \multirow[t]{2}{*}{ Math Score } & 0.165 & 0.077 & 0.166 & 0.166 \\
\hline & $(0.010)$ & $(0.006)$ & $(0.010)$ & $(0.010)$ \\
\hline \multirow[t]{2}{*}{ Word Knowledge } & 0.050 & 0.013 & 0.050 & 0.050 \\
\hline & $(0.010)$ & $(0.007)$ & $(0.010)$ & $(0.010)$ \\
\hline \multirow[t]{2}{*}{ General Science } & 0.067 & 0.042 & 0.065 & 0.066 \\
\hline & $(0.015)$ & $(0.012)$ & $(0.015)$ & $(0.015)$ \\
\hline \multirow[t]{2}{*}{ Automotive Knowledge } & -0.067 & -0.031 & -0.066 & -0.066 \\
\hline & $(0.011)$ & $(0.007)$ & $(0.011)$ & $(0.011)$ \\
\hline \multirow[t]{2}{*}{ Highest Grade Father } & 0.051 & -0.040 & 0.051 & 0.051 \\
\hline & $(0.016)$ & $(0.028)$ & $(0.016)$ & $(0.016)$ \\
\hline \multirow[t]{2}{*}{ Highest Grade Mother } & 0.038 & 0.074 & 0.038 & 0.038 \\
\hline & $(0.022)$ & $(0.053)$ & $(0.022)$ & $(0.022)$ \\
\hline \multirow[t]{2}{*}{ Number of Siblings } & -0.046 & -0.013 & -0.046 & -0.012 \\
\hline & $(0.016)$ & $(0.011)$ & $(0.016)$ & $(0.038)$ \\
\hline \multirow[t]{2}{*}{ Family Income } & 0.092 & 0.068 & -0.008 & 0.095 \\
\hline & $(0.022)$ & $(0.017)$ & $(0.068)$ & $(0.022)$ \\
\hline Black $\times$ & -0.330 & & & \\
\hline College in County & $(0.220)$ & & & \\
\hline Hispanic $\times$ & -0.635 & & & \\
\hline College in County & $(0.390)$ & & & \\
\hline Highest Grade Father $\times$ & & 0.071 & & \\
\hline College in County & & $(0.030)$ & & \\
\hline Highest Grade Mother $\times$ & & -0.065 & & \\
\hline College in County & & $(0.055)$ & & \\
\hline Family Income $x$ & & & 0.111 & \\
\hline College in County & & & $(0.067)$ & \\
\hline Number of Siblings $\times$ & & & & -0.039 \\
\hline College in County & & & & $(0.041)$ \\
\hline Sample Size & 2404 & 2404 & $2 \overline{2404}$ & 2404 \\
\hline
\end{tabular}




\section{Table 8}

Results From Structural Schooling Model

Estimated Without Borrowing Constraints (Standard Errors in Parentheses) $^{\S}$

\begin{tabular}{|c|c|c|c|}
\hline \multicolumn{4}{|c|}{ 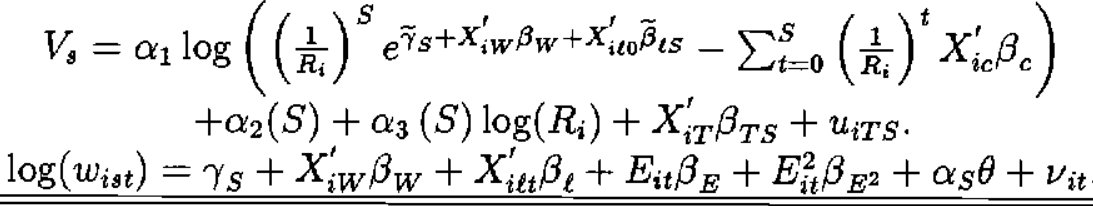 } \\
\hline & $\begin{array}{c}\text { Graduate } \\
\text { High School }\end{array}$ & $\begin{array}{l}\text { Attend } \\
\text { College }\end{array}$ & $\begin{array}{l}\text { Graduate } \\
\text { College }\end{array}$ \\
\hline Black & $\begin{array}{c}0.855 \\
(0.169)\end{array}$ & $\begin{array}{c}1.215 \\
(0.202)\end{array}$ & $\begin{array}{c}1 . \overline{570} \\
(0.252)\end{array}$ \\
\hline Hispanic & $\begin{array}{c}0.136 \\
(0.187)\end{array}$ & $\begin{array}{c}0.488 \\
(0.212)\end{array}$ & $\begin{array}{c}0.539 \\
(0.279)\end{array}$ \\
\hline AFQT Score & $\begin{array}{c}0.045 \\
(0.005)\end{array}$ & $\begin{array}{c}0.054 \\
(0.008)\end{array}$ & $\begin{array}{c}0.101 \\
(0.019)\end{array}$ \\
\hline Father Dropout & $\begin{array}{c}-0.055 \\
(0.144)\end{array}$ & $\begin{array}{l}-0.123 \\
(0.158)\end{array}$ & $\begin{array}{c}-0.028 \\
(0.198)\end{array}$ \\
\hline Father Some Coll & $\begin{array}{c}0.076 \\
(0.258)\end{array}$ & $\begin{array}{c}0.233 \\
(0.273)\end{array}$ & $\begin{array}{c}0.603 \\
(0.293)\end{array}$ \\
\hline Father Coll Grad & $\begin{array}{c}0.445 \\
(0.349)\end{array}$ & $\begin{array}{c}0.618 \\
(0.359)\end{array}$ & $\begin{array}{c}1.322 \\
(0.357)\end{array}$ \\
\hline Mother Dropout & $\begin{array}{c}-0.142 \\
(0.140)\end{array}$ & $\begin{array}{c}-0.227 \\
(0.157)\end{array}$ & $\begin{array}{c}-0.392 \\
(0.209)\end{array}$ \\
\hline Mother Some Coll & $\begin{array}{c}0.077 \\
(0.295)\end{array}$ & $\begin{array}{c}-0.162 \\
(0.318)\end{array}$ & $\begin{array}{c}0.376 \\
(0.319)\end{array}$ \\
\hline Mother Coll Grad & $\begin{array}{c}0.200 \\
(0.396)\end{array}$ & $\begin{array}{c}0.332 \\
(0.406)\end{array}$ & $\begin{array}{c}0.907 \\
(0.417)\end{array}$ \\
\hline Number of Siblings & $\begin{array}{c}-0.029 \\
(0.042)\end{array}$ & $\begin{array}{c}-0.092 \\
(0.047)\end{array}$ & $\begin{array}{c}-0.124 \\
(0.055)\end{array}$ \\
\hline Family Income & $\begin{array}{c}0.162 \\
(0.043)\end{array}$ & $\begin{array}{c}0.121 \\
(0.045)\end{array}$ & $\begin{array}{c}0.136 \\
(0.054)\end{array}$ \\
\hline Region & Yes & Yes & Yes \\
\hline
\end{tabular}

(Continued on Following Page) 
Table 8 (Continued)

\begin{tabular}{|c|c|c|c|c|}
\hline \multicolumn{5}{|c|}{ Local Labor Market Parameters ${ }^{\ddagger}\left(\beta_{l}\right)$} \\
\hline & Attend & Graduate & Attend & Graduate \\
\hline & High School & High School & College & College \\
\hline Intercept & & & $\begin{array}{c}5.689 \\
(0.417)\end{array}$ & $\begin{array}{c}5.236 \\
(0.338)\end{array}$ \\
\hline Local Income 17-18 & $\begin{array}{c}0.044 \\
(0.047)\end{array}$ & $\begin{array}{c}0.009 \\
(0.022)\end{array}$ & & \\
\hline $\begin{array}{l}\text { Mean Loc Inc over } \\
\text { Working Life }\end{array}$ & 0.302 & 0.293 & 0.300 & 0.300 \\
\hline \multicolumn{5}{|c|}{ Additional Parameters } \\
\hline Scale & & $\begin{array}{c}1.281 \\
(0.140)\end{array}$ & & \\
\hline High School Nesting $\left(\rho_{H}\right)$ & & $\begin{array}{c}0.452 \\
(0.146)\end{array}$ & & \\
\hline College Nesting $\left(\rho_{C}\right)$ & & 1.000 & & \\
\hline & & $(-)$ & & \\
\hline
\end{tabular}


Table 9

Results for Tests of Borrowing Constraints

From Structural Model

(P-value of Pseudo Likelihood Ratio Test in Parentheses) ${ }^{\dagger}$

\begin{tabular}{|c|c|c|}
\hline Specification & $\begin{array}{l}\text { Rate of } \\
\text { Return } \ddagger\end{array}$ & $\begin{array}{c}\text { Negative } \\
\text { Log-Likelihood }\end{array}$ \\
\hline Unrestricted: & & 2547.69 \\
\hline Everyone & 1.031 & \\
\hline Racial Groups: & & 2547.35 \\
\hline Whites & 1.031 & $(0.712)$ \\
\hline Blacks & 1.000 & \\
\hline Hispanics & 1.000 & \\
\hline Parents Education: & & 2546.41 \\
\hline Both College Educated & 1.031 & $(0.278)$ \\
\hline Father $12 \Gamma$ Mother 12 & 1.000 & \\
\hline Father 12ГMother Coll & 1.000 & \\
\hline Father Coll $\Gamma$ Mother12 & 1.034 & \\
\hline Family Income: & & 2546.90 \\
\hline Top Third & 1.031 & $(0.454)$ \\
\hline Middle Third & 1.032 & \\
\hline Bottom Third & 1.037 & \\
\hline Number of Siblings*: & & 2547.68 \\
\hline Zeros & 1.031 & $(0.990)$ \\
\hline Two & 1.031 & \\
\hline Four & 1.031 & \\
\hline
\end{tabular}

$\dagger$ These p-values are not strictly correct since we have not corrected for the fact that the coefficients of the wage regression were estimated

\# The "market rate of return" is fixed to be 1.03

* In the other cases we interacted the rate with dummy variables. In this one we just interact it with the number of siblings. 
Table 10

Results from Structural Schooling Model

Allowing For Unobserved Heterogeneity in Borrowing Rates

\begin{tabular}{|c|c|c|c|}
\hline \multicolumn{4}{|c|}{ 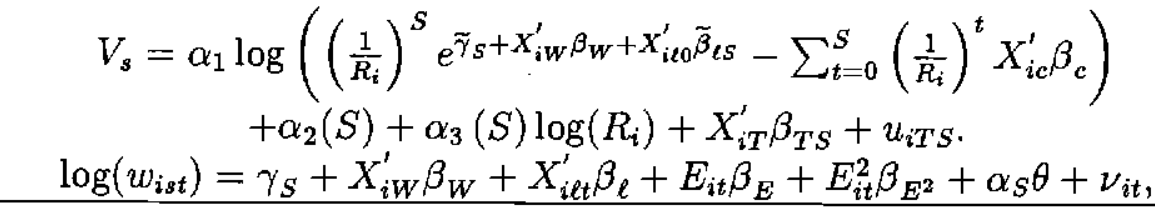 } \\
\hline \multicolumn{4}{|c|}{ Distribution of Borrowing Rates $\left(R_{i}\right)$} \\
\hline Rates & 1.030 & 1.071 & \\
\hline Probability & 1.00 & 0.00 & \\
\hline \multicolumn{4}{|c|}{ Wage Equation } \\
\hline AFQT Score & 0.007 & & \\
\hline Local Income & 0.027 & & \\
\hline Black & -0.095 & & \\
\hline Hispanic & -0.047 & & \\
\hline Experience & 0.064 & & \\
\hline Experience $^{2}$ & -0.002 & & \\
\hline Intercept-Dropout & 1.046 & & \\
\hline Intercept-HS Grad & 1.139 & & \\
\hline Intercept-Some Coll & 1.031 & & \\
\hline Intercept-Coll Grad & 1.324 & & \\
\hline Factor Loading-Dropout $\left(\alpha_{0}\right)$ & 0.176 & & \\
\hline Factor Loading-Dropout $\left(\alpha_{1}\right)$ & 0.155 & & \\
\hline Factor Loading-Dropout $\left(\alpha_{2}\right)$ & 0.153 & & \\
\hline Factor Loading-Dropout $\left(\alpha_{3}\right)$ & 0.069 & & \\
\hline Family Background & Yes & & \\
\hline Geographic Controls & Yes & & \\
\hline \multicolumn{4}{|c|}{ Taste Parameters $\left(\beta_{T}\right)$} \\
\hline & Graduate & Attend & Graduate \\
\hline & High School & College & College \\
\hline Black & 0.632 & 1.725 & 1.873 \\
\hline Hispanic & 0.057 & 0.838 & 0.793 \\
\hline AFQT Score & 0.043 & 0.088 & 0.128 \\
\hline Father Dropout & -0.144 & -0.235 & -0.108 \\
\hline Father Some Coll & 0.051 & 0.678 & 0.900 \\
\hline Father Coll Grad & 0.317 & 1.243 & 1.683 \\
\hline Mother Dropout & -0.166 & -0.482 & -0.662 \\
\hline Mother Some Coll & 0.144 & -0.271 & 0.336 \\
\hline Mother Coll Grad & 0.198 & 0.650 & 1.244 \\
\hline Number of Siblings & -0.265 & -0.113 & -0.099 \\
\hline Factor Loading $\left(\delta_{T}\right)$ & 0.000 & 2.130 & 2.130 \\
\hline Region & Yes & Yes & Yes \\
\hline
\end{tabular}

(Continued on Following Page) 


\section{Table 10 (Continued)}

\begin{tabular}{|c|c|c|c|c|}
\hline \multicolumn{5}{|c|}{ Local Labor Market Parameters $\left(\beta_{l}\right)$} \\
\hline & Attend & Graduate & Attend & Graduate \\
\hline & High School & High School & $\begin{array}{c}\text { College } \\
2.746\end{array}$ & $\begin{array}{c}\text { College } \\
3.225\end{array}$ \\
\hline & 0.408 & 0.258 & & \\
\hline L & 0.245 & 0.172 & 0.300 & 0.300 \\
\hline
\end{tabular}

Intercept

Additional Parameters

Scale

0.231

High School Nesting $\left(\rho_{H}\right) \quad 0.452$

College Nesting $\left(\rho_{C}\right)$ 1.000

${ }^{\dagger}$ In this set of estimates we fixed the interest rate so that $1 /(1+r)=\delta=0.97$. 